\title{
Resonance Scattering Detection Using the CSU-CHILL Dual-Wavelength, Dual-Polarization Radar
}

\author{
FRANCESC JUNYENT AND V. CHANDRASEKAR \\ Electrical and Computer Engineering, Colorado State University, Fort Collins, Colorado \\ P. KENNEDY \\ Atmospheric Science, Colorado State University, Fort Collins, Colorado
}

(Manuscript received 9 May 2018, in final form 2 April 2019)

\begin{abstract}
The CSU-CHILL radar is a dual-wavelength, dual-polarization weather radar system operating at S and X band with coaxial beams. This radar system offers a unique environment to develop and/or validate algorithms that cut across its wavelengths and polarizations. This paper presents a method to retrieve resonance scattering regions from the difference in intrinsic reflectivities after attenuation correction, which is performed using measured reflectivity fields only. The algorithm to retrieve these regions dominated by nonRayleigh scattering is applied to different storm events, and the obtained data field capturing the difference in $\mathrm{S}$ - and X-band reflectivities due to resonance effects (which we will call Mie signal for convenience) is compared to the collocated dual-polarization fields. The obtained Mie signal is also compared to hail reports. In both cases, the retrieved Mie signal is found to be consistent with the rest of the dual-polarization data fields, and in some situations, it is shown to bring information not directly discernible from the usual dual-polarization radar variables.
\end{abstract}

\section{Introduction}

The Colorado State University (CSU)-University of Chicago-Illinois State Water Survey (CSU-CHILL) National Weather Radar Facility (Brunkow et al. 2000) located in Greeley, Colorado, is a research facility operated by CSU, under the sponsorship of the National Science Foundation (NSF) and CSU. The CSU-CHILL radar went through a major transformation (Junyent et al. 2015) to add support for simultaneous dual-wavelength ( $\mathrm{S}$ and $\mathrm{X}$ band), dual-polarization (linear horizontal and vertical at both wavelengths) radar operation, as well as highpolarization purity single-wavelength operation at $\mathrm{S}$ or $\mathrm{X}$ band [see Junyent et al. (2015) for a list of the main radar characteristics].

Dual-wavelength weather radar systems have historically been used to estimate precipitation properties through the use of the dual-wavelength ratio (DWR), defined as the ratio between reflectivity at the longer wavelength and reflectivity at the shorter wavelength.

\footnotetext{
Corresponding author: Francesc Junyent, francesc@ engr.colostate.edu
}

The DWR signal captures the difference in propagation effects (i.e., attenuation) as the radiation at the two wavelengths travels through the medium, as well as the difference in scattering magnitudes (owing to resonance effects in particles with sizes in the order of the wavelength of incident radiation). A lot of emphasis has been put in interpreting the scattering magnitude contribution to the DWR (i.e., the contribution due to the relative size of the scatterer with respect to each radiated wavelength) as it could indicate the presence of large hydrometeors including hail (Atlas and Ludlam 1961; Eccles and Atlas 1973; Jameson and Srivastava 1978; Jameson and Heymsfield 1980; Bringi et al. 1986a; Tuttle et al. 1989; Herzegh and Jameson 1992). In all cases the X-band signal attenuation effect in the DWR was treated as an obstacle to get to the hail detection, and was tackled a few different ways: using the increments in measured DWR at consecutive ranges (Eccles and Mueller 1971), through the use of the range derivative of the DWR (Carbone et al. 1973), using a least squares piecewise linear fit to the DWR to obtain a monotonically increasing attenuation signal (Jameson and Heymsfield 1980), or by using the DWR values at the farther edge of 
the storm to indicate the total attenuation at the shorter wavelength and apportioning it according to the unattenuated longer-wavelength reflectivity values measured along the signal path (Tuttle and Rinehart 1983). Some of these techniques are still in use today, with Louf et al. (2014) proposing a hail detector for aviation radar using an implementation of the DWR range-derivative method.

Other uses of multiwavelength data (although not necessarily at the same frequencies and antenna configurations as presented in this paper) have appeared over time. Gaussiat et al. (2003) proposed a threefrequency $(3,35$, and $94 \mathrm{GHz})$ method to obtain differential attenuation in the presence of non-Rayleigh scatterers, while Ellis and Vivekanandan (2010) used collocated radars at different wavelengths ( $\mathrm{S}$ and Ka band) to determine the gaseous attenuation of the higher frequency when propagating through clear air using the leading edge of a storm to obtain total attenuation. In Picca and Ryzhkov (2012) data from two separate radars observing a common storm at different wavelengths ( $\mathrm{S}$ and $\mathrm{C}$ band) were used to study their respective hail polarimetric signatures and relation to hail size, while Bodine et al. (2014) used data from the same two separate radars to study and compare their respective tornadic debris polarimetric signatures. Kneifel et al. (2015) proposed a three-frequency $(9.7,35.3$, and $95 \mathrm{GHz})$ method to retrieve microphysical snow properties with vertically pointing radars, whereas Tridon et al. $(2013,2017)$ used the ratio of spectrums at different wavelengths $(\mathrm{Ka}$ and $\mathrm{W}$ band) to separate attenuation from Mie effects and obtain rainfall.

As an independent development from dual-wavelength, dual-polarization radars [using two equal power transmitted signals radiated at orthogonal polarization statestypically linear horizontal and vertical as proposed in Seliga and Bringi $(1976,1978)]$ have become a mature and successful technology (Doviak and Zrnić 1993; Bringi and Chandrasekar 2001), which is now nearly ubiquitous. Dual-polarization radar is being used to research hail [as reported in Bringi et al. (1986a,b), Vivekanandan et al. (1990), and Ryzhkov et al. (2013a,b)] using shape-derived information (as opposed to size in the dual-wavelength case) as the discriminating factor. Dual-polarization signal processing is also at the foundation of attenuation correction (Testud et al. 2000).

With all these signal processing techniques available to process dual-wavelength and dual-polarization datasets, the CSU-CHILL radar provides a unique environment to develop and apply such techniques on a modern dualwavelength, dual-polarization scanning radar system with coaxial beams (i.e., beams radiated through the same antenna and along the same direction). This paper leverages such a technique for attenuation correction and applies it in a novel way to both provide attenuation correction and obtain any resonance scattering signal present after that correction. A Mie signal (which we will use as shorthand for "difference in scattering magnitudes due to resonance effects") retrieval algorithm is devised using this technique, and results comparing the retrieved Mie signal to other dual-polarization fields and hail reports are presented.

\section{Resonance scattering and attenuation}

Weather radar systems rely on the weather radar equation to derive reflectivity $Z$ from the received echo signal power $P_{R}$, assuming that the transmitted peak power $P_{T}$, the antenna gain on transmission $G_{T}$, the illuminated volume $\Delta V$, the range to the illuminated volume $R$, and the antenna effective area on reception $A_{e}$ are known. Reflectivity $Z$ is obtained from the average radar cross-section area per unit of volume $\eta$ as shown below:

$$
\begin{gathered}
P_{R}=P_{T} \frac{G_{T}}{4 \pi R^{2}} \frac{\eta \Delta V}{4 \pi R^{2}} A_{e}, \\
\eta=\frac{\pi^{5}}{\lambda^{4}}\left|K_{W}\right|^{2} Z .
\end{gathered}
$$

In general, $Z$ is defined as

$$
Z=\frac{\lambda^{4}}{\pi^{5}\left|K_{W}\right|^{2}} \int_{0}^{\infty} \sigma(D) N(D) d D
$$

for any scatterers. In the case of Rayleigh spherical water drops, the scattering cross section $\sigma$ becomes

$$
\sigma(D)=\frac{\pi^{5}}{\lambda^{4}}\left|K_{W}\right|^{2} D^{6},
$$

and reflectivity simplifies to

$$
Z=\int_{0}^{\infty} D^{6} N(D) d D
$$

The dominant scattering regime (Rayleigh, Mie/resonance, optical) is determined both by hydrometeor dielectric constant (lower dielectric constants produce weaker resonances) and by the ratio of hydrometeor size to illuminating wavelength, as illustrated in Fig. 1 for a simple sphere case. The additional axes in the figure show where the different scattering regimes fall at $S$ band and $\mathrm{X}$ band (the CSU-CHILL radar operating frequencies). A diameter size of $\sim 6 \mathrm{~mm}$ would put a scatterer in the Mie region at X band, while still in the Rayleigh region at $S$ band. A diameter size of $\sim 22 \mathrm{~mm}$ would put a scatterer in the Mie region at $\mathrm{S}$ band, and 


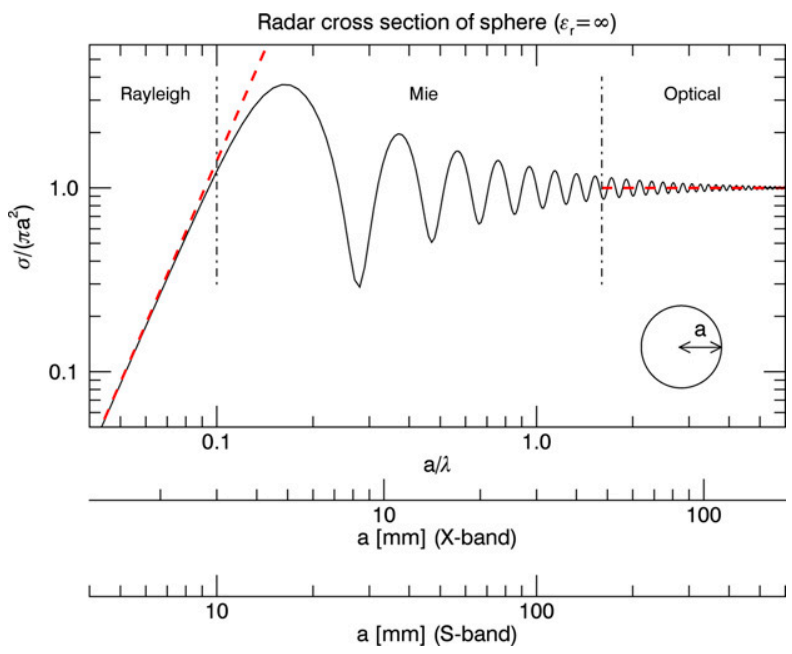

FIG. 1. Normalized radar cross section of a conductive sphere vs normalized sphere radius. Additional axes show equivalent sphere radius at $\mathrm{X}$ band and $\mathrm{S}$ band. One can clearly see how the Mie scattering regime is achieved earlier at $\mathrm{X}$ band.

into the optical regime at $\mathrm{X}$ band. The fact that certain size scatterers will be in different scattering regimes depending on the wavelength used to illuminate them can be exploited to make inferences about the scatterer size (assuming the dielectric constant is known or not changing) through the difference in reflectivities measured at each wavelength.

This is illustrated in Fig. 2, showing an example of the difference in intrinsic reflectivities at 2.75 and $9.4 \mathrm{GHz}$, for the case of oblate (using the Beard-Chuang axisratio model) liquid water and spherical ice static particles, obtained using the T-matrix method with a liquid water temperature of $15^{\circ} \mathrm{C}$ and ice temperature of $-10^{\circ} \mathrm{C}$. In the liquid water case one can see that for very large drop diameters (over $9 \mathrm{~mm}$, which should be very rare) the difference signal increases very rapidly and to very high values, whereas in the ice case the increase is more gradual and shows some fluctuation. Although a very simplified example (more realistically the radar resolution volume will see a distribution of hydrometeor sizes with varying proportions of liquid water and ice), and assuming that the very large drop diameters $(>9 \mathrm{~mm})$ needed to create a large positive difference $(>3 \mathrm{~dB})$ in intrinsic reflectivities in the liquid water case will be rare, the difference of reflectivities at $\mathrm{S}$ and $\mathrm{X}$ band has the potential to indicate the presence of hailstones (Atlas and Ludlam 1961; Eccles and Atlas 1973; Jameson and Srivastava 1978; Jameson and Heymsfield 1980; Bringi et al. 1986a; Tuttle et al. 1989; Herzegh and Jameson 1992). However, in order to make use of the difference in reflectivities to detect hail (or large particles in general), any attenuation of the reflectivity

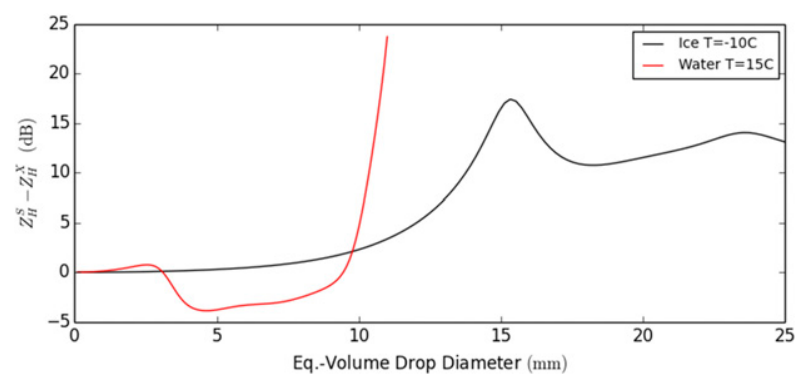

FIG. 2. Difference in intrinsic reflectivities at $\mathrm{S}$ band and $\mathrm{X}$ band for water (oblate) and ice (spherical) single particles, showing increasing values for larger diameters as particles enter the Mie scattering regime at the higher frequency.

measured at $\mathrm{X}$ band needs to be corrected to ensure that the observed dual-wavelength reflectivity difference is due to different dominant scattering regimes (Rayleigh vs Mie) and not propagation effects. The following expression shows the general relationship between measured reflectivity at $\mathrm{S}$ and $\mathrm{X}$ band:

$$
Z_{S}(r)=Z_{X}^{\prime}(r)+2 \operatorname{PIA}\left(r_{o} ; r\right)+\operatorname{MIE}_{X}(r)+\varepsilon(r),
$$

where $Z_{S}(r)$ is the reflectivity measured at $\mathrm{S}$ band, $Z_{X}^{\prime}(r)$ is the reflectivity measured at $\mathrm{X}$ band (both in $\mathrm{dBZ}$ ), $\operatorname{PIA}\left(r_{o} ; r\right)$ is the one-way path-integrated attenuation $(\mathrm{dB})$ experienced by the X-band reflectivity signal in the considered data ray region from $r_{o}$ to $r, \operatorname{MIE}_{X}(r)$ is the component due to the possible difference in scattering regimes at the two wavelengths, and $\varepsilon(r)$ is a term accounting for measurement artifacts introduced by the radar itself (including those that may be created by mismatched beam volumes, and any relative offsets in S- and X-band reflectivity calibration). Assuming that the radar is well calibrated and no significant artifacts are introduced by beam mismatch, we will treat $\varepsilon(r)$ as negligible.

For the case of a dual-wavelength radar at $\mathrm{S}$ and $\mathrm{X}$ band such as the CSU-CHILL radar a method to correct the attenuation at $\mathrm{X}$ band based on minimizing a cost function was introduced in Junyent and Chandrasekar (2016):

$$
\begin{aligned}
\min _{\operatorname{PIA}\left(r_{o} ; r_{m}\right)} f(\mathrm{PIA})= & w(r) \| Z_{S}(r)-\left[Z_{X}^{\prime}(r)\right. \\
& \left.+2 \operatorname{PIA}\left(r_{0} ; r\right)\right] \|, \quad r_{0} \leq r \leq r_{m}
\end{aligned}
$$

where $w(r)$ is a set of weights applicable during the minimization process. This cost function involves reflectivities only and can be solved using the rain profiling algorithm in Testud et al. (2000) to compute the optimal path-integrated attenuation along the ray PIA $\left(r_{0} ; r\right)$ that yields the minimum error between $\mathrm{S}$ - and X-band reflectivities, with total path-integrated attenuation 
$\operatorname{PIA}\left(r_{o} ; r_{m}\right)$ as the variable to optimize over [in lieu of the differential propagation phase increment and/or alpha terms, or other differential-phase-based constraints used in typical dual-polarization applications such as Carey et al. (2000), Bringi et al. (2001), Ryzhkov et al. (2006, 2007), and Gu et al. (2011)]. Because the technique relies on reflectivity measurements only, the dual-wavelength attenuation correction algorithm performance should be independent of antenna pointing angle, which is a benefit of this scheme.

Equation (6) can be solved by finding $\operatorname{PIA}\left(r_{0} ; r\right)$ that minimizes its $l^{2}$ norm (also sometimes called the Euclidian norm and defined as $|\mathbf{x}|=\sqrt{\sum_{k=1}^{n}\left|x_{k}\right|^{2}}$ ) using the propagation equation in Testud et al. (2000) and Bringi and Chandrasekar (2001). Following the formulation for the propagation equation as presented in chapter 7 of Bringi and Chandrasekar (2001), one can see that the path-integrated attenuation along the data ray $\operatorname{PIA}\left(r_{o} ; r\right)$ can be expressed as

$$
\begin{aligned}
\operatorname{PIA}\left(r_{o} ; r\right) & =\int_{r_{o}}^{r} A(s) d s, \\
A(r) & =\frac{\left[Z_{X}^{\prime}(r)\right]^{b}\left[e^{(4 b / \gamma) \operatorname{PIA}\left(r_{o} ; r_{m}\right)}-1\right]}{I\left(r_{o} ; r_{m}\right)+\left[e^{(4 b / \gamma) \operatorname{PIA}\left(r_{o} ; r_{m}\right)}-1\right] I\left(r ; r_{m}\right)}, \\
I\left(r ; r_{m}\right) & =\frac{4 b}{\gamma} \int_{r}^{r_{m}}\left[Z_{X}^{\prime}(r)\right]^{b} d r \\
\gamma & =20 \log (e), \\
b & =0.8
\end{aligned}
$$

where $A(r)$ is specific attenuation and $b$ is a parameter typically within $0.6-0.9$ at microwave frequencies and close to 0.8 at X band (Delrieu et al. 1997; Testud et al. 2000; Park et al. 2005). Note that the usual dualpolarization constraint $\alpha \Delta \Phi_{\mathrm{dp}}\left(r_{o} ; r_{m}\right)$ is changed for its explicit form PIA $\left(r_{o} ; r_{m}\right)$ in Eq. (4b). Combining Eqs. (6) and (7) the resulting cost function can be solved for the total path-integrated attenuation PIA $\left(r_{o} ; r_{m}\right)$ that yields the along-ray path-integrated attenuation $\operatorname{PIA}\left(r_{o} ; r\right)$ that minimizes the difference between the measured S-band and X-band reflectivities as shown in Eq. (6), using a method for solving nonlinear least squares problems such as Levenberg-Marquardt (Levenberg 1944; Marquardt 1963). This dual-wavelength attenuation correction procedure is used throughout the paper to estimate and correct for attenuation in the X-band signal.

In the simplest case of dealing with data where there is no difference in intrinsic reflectivities [i.e., $\operatorname{MIE}_{X}(r) \rightarrow 0$ in Eq. (5)] and the attenuation to reflectivity relationship

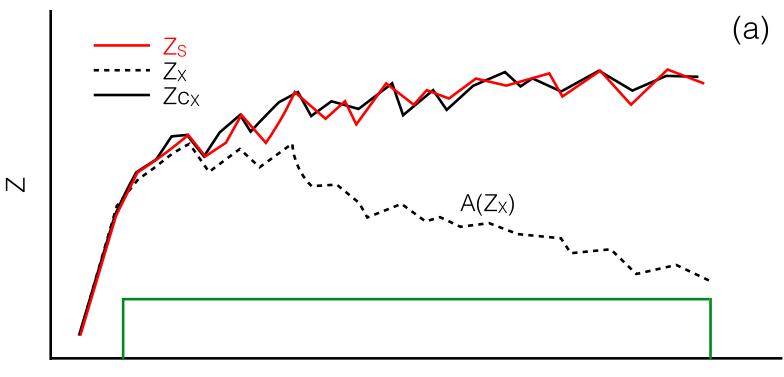

(a)
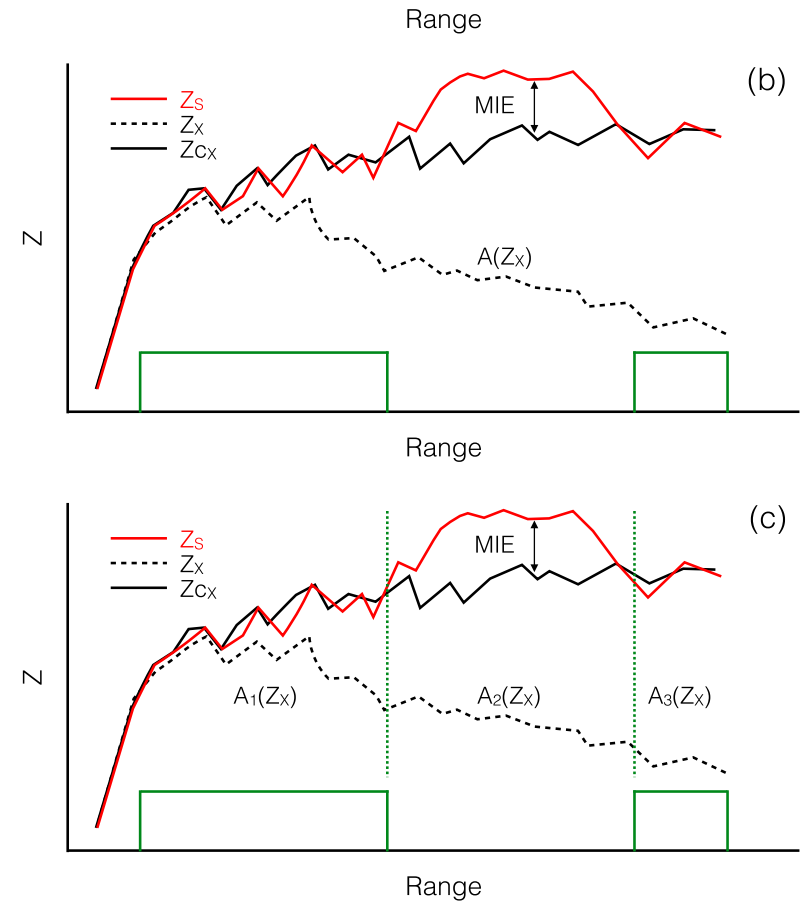

FIG. 3. Attenuation-correction scenarios. (a) The simplest case, assuming a fixed relationship between attenuation and reflectivity along the profile and no presence of resonance scattering regions. In that situation, the attenuation correction algorithm can be applied with uniform weights along the data profile. (b) As in (a), but including a region of resonance scattering. In that situation the attenuation-correction algorithm can be applied along the data profile lowering the weights over the resonance scattering region to avoid biasing the results. (c) Assuming changing relationships along the data profile regions and the presence of a resonance scattering region. In that situation the attenuation-correction algorithm can be applied piecewise along the different regions.

can be assumed to be fixed throughout the considered range $\left\{A(r)=a\left[Z_{X}^{\prime}(r)\right]^{b}\right.$, e.g., in stratiform rain below the melting layer\}, one can apply the attenuation correction expression in Eq. (6) with uniform weights over the entire data ray:

$$
w(r)=1, \quad r_{0} \leq r \leq r_{m},
$$

as illustrated in Fig. 3a.

In the case of resonance scattering being present in certain locations [i.e., $\operatorname{MIE}_{X}(r)>0, r_{1}<r<r_{2}$ such as 
in having a difference in intrinsic reflectivities due to larger hydrometeors in the $r_{1}, r_{2}$ data ray region] while maintaining a fixed attenuation to reflectivity relationship along the entire data ray $\left\{A(r)=a\left[Z_{X}^{\prime}(r)\right]^{b}\right\}$, one can use a nonuniform set of weights to avoid biasing the attenuation correction results in the region of resonance. The example weights below assume a region dominated by resonance regime scattering between $r_{1}$ and $r_{2}$ :

$$
w(r)= \begin{cases}1, & r_{0} \leq r \leq r \\ 0, & r_{1}<r<r_{2} . \\ 1, & r_{2} \leq r \leq r_{m}\end{cases}
$$

The region of resonance scattering between $r_{1}$ and $r_{2}$ would be suppressed from the minimization calculation in Eq. (6) by the zero value weights, while still used in the path-integrated attenuation calculation in Eq. (7). This illustrated in Fig. 3b.

In the case of changing relationships between attenuation and reflectivity along data ray regions $\{A(r)=$ $\left.a_{0}\left[Z_{X}^{\prime}(r)\right]^{b}, r_{0}<r<r_{1} ; A(r)=a_{1}\left[Z_{X}^{\prime}(r)\right]^{b}, r_{2}<r<r_{3} ; \ldots\right\}$ and the presence of a resonance scattering region as illustrated in Fig. 3c, one can apply the attenuation correction method piecewise.

Rewriting Eq. (6) splitting the along-ray path-integrated attenuation $\operatorname{PIA}\left(r_{o} ; r\right)=\operatorname{PIA}\left(r_{o} ; r_{i}\right)+\operatorname{PIA}\left(r_{i} ; r\right)$ into an attenuation offset term PIA $\left(r_{o} ; r_{i}\right)$ at the beginning of the considered ray region plus the reminder of the along-ray path-integrated attenuation $\operatorname{PIA}\left(r_{i} ; r\right)$ as in below,

$$
\min _{\operatorname{PIA}\left(r_{o} ; r_{i}\right), \operatorname{PIA}\left(r_{i} ; r_{m}\right)} f(\mathrm{PIA})=w(r)\left\|Z_{S}(r)-\left\{Z_{X}^{\prime}(r)+2\left[\mathrm{PIA}\left(r_{0} ; r_{i}\right)+\operatorname{PIA}\left(r_{i} ; r\right)\right]\right\}\right\|, \quad r_{0} \leq r_{i}<r \leq r_{m},
$$

it can now be applied to a section anywhere in the data profile-the attenuation offset term $\operatorname{PIA}\left(r_{o} ; r_{i}\right)$ accounts for any attenuation accumulated up to the beginning $r_{i}$ of the section under correction, and now becomes a second optimization variable in addition to the total path-integrated attenuation $\operatorname{PIA}\left(r_{i} ; r_{m}\right)$ along the considered ray region as introduced in Eq. (6).

Therefore, one can address the general case of a data ray composed of regions with changing relationships between attenuation and reflectivity (note that as shown so far we assume all variability to come from the leading coefficient $a$ while $b$ is considered constant) and the presence of a resonance scattering region, by applying the attenuation correction optimization in Eq. (10) along the regions dominated by Rayleigh scattering and using the difference in attenuation at the end of a Rayleigh region and the beginning of the next Rayleigh region as the constraint for the attenuation correction using Eq. (4) of a resonance scattering region in between. This is shown in the expression below:

$\min _{\operatorname{PIA}\left(r_{o} ; r_{i}\right), \operatorname{PIA}\left(r_{i} ; r_{i+1}\right)} f(\mathrm{PIA})=\left\{\begin{array}{lc}\left\|10 \log \left[Z_{S}(r)\right]-\left\{10 \log \left[Z_{X}^{\prime}(r)\right]+2 \operatorname{PIA}\left(r_{0} ; r\right)\right\}\right\|, & r_{0} \leq r \leq r_{1} \\ 2\left[\operatorname{PIA}\left(r_{0} ; r_{1}\right)+\operatorname{PIA}\left(r_{1} ; r\right)\right], & r_{1}<r<r \\ \left\|10 \log \left[Z_{S}(r)\right]-\left\{10 \log \left[Z_{X}^{\prime}(r)\right]+2\left[\operatorname{PIA}\left(r_{0} ; r_{2}\right)+\operatorname{PIA}\left(r_{2} ; r\right)\right]\right\}\right\|, & r_{2} \leq r \leq r \\ 2\left[\operatorname{PIA}\left(r_{0} ; r_{3}\right)+\operatorname{PIA}\left(r_{3} ; r\right)\right], & r_{3}<r<r_{4} \\ \vdots & \vdots \\ \left\|10 \log \left[Z_{S}(r)\right]-\left\{10 \log \left[Z_{X}^{\prime}(r)\right]+2\left[\operatorname{PIA}\left(r_{0} ; r_{i}\right)+\operatorname{PIA}\left(r_{i} ; r\right)\right]\right\}\right\|, & r_{i} \leq r \leq r_{m} .\end{array}\right.$.

In all cases the resulting attenuation-corrected X-band reflectivity $Z_{X}(r)$ allows obtaining the Mie signal variable as

$$
\begin{array}{r}
\operatorname{MIE}_{X}(r)=10 \log \left[Z_{S}(r)\right]-10 \log \left[Z_{X}(r)\right] \\
\approx \operatorname{DWR}(r)-2 \operatorname{PIA}\left(r_{o} ; r\right) .
\end{array}
$$

It is worth noting that no attempt is made to correct reflectivity at $\mathrm{S}$ band for any potential attenuation. $\mathrm{Al}$ though this should not bias the result in Eq. (9), in the case of attenuation present in the S-band reflectivity [such as in small melting hail as described in Ryzhkov et al. (2013a)] it will also be present in the attenuationcorrected version of the X-band reflectivity.

\section{Mie signal algorithm}

As the two wavelength components of the CSU-CHILL radar have different antenna beam widths (Junyent et al. 2015), the initial step in all data processing results shown throughout the paper is to synthesize X-band measurements that match the wider $1^{\circ} \mathrm{S}$-band beamwidth using the method described in the appendix. This is done with the intent of reducing any potential errors due to beam 

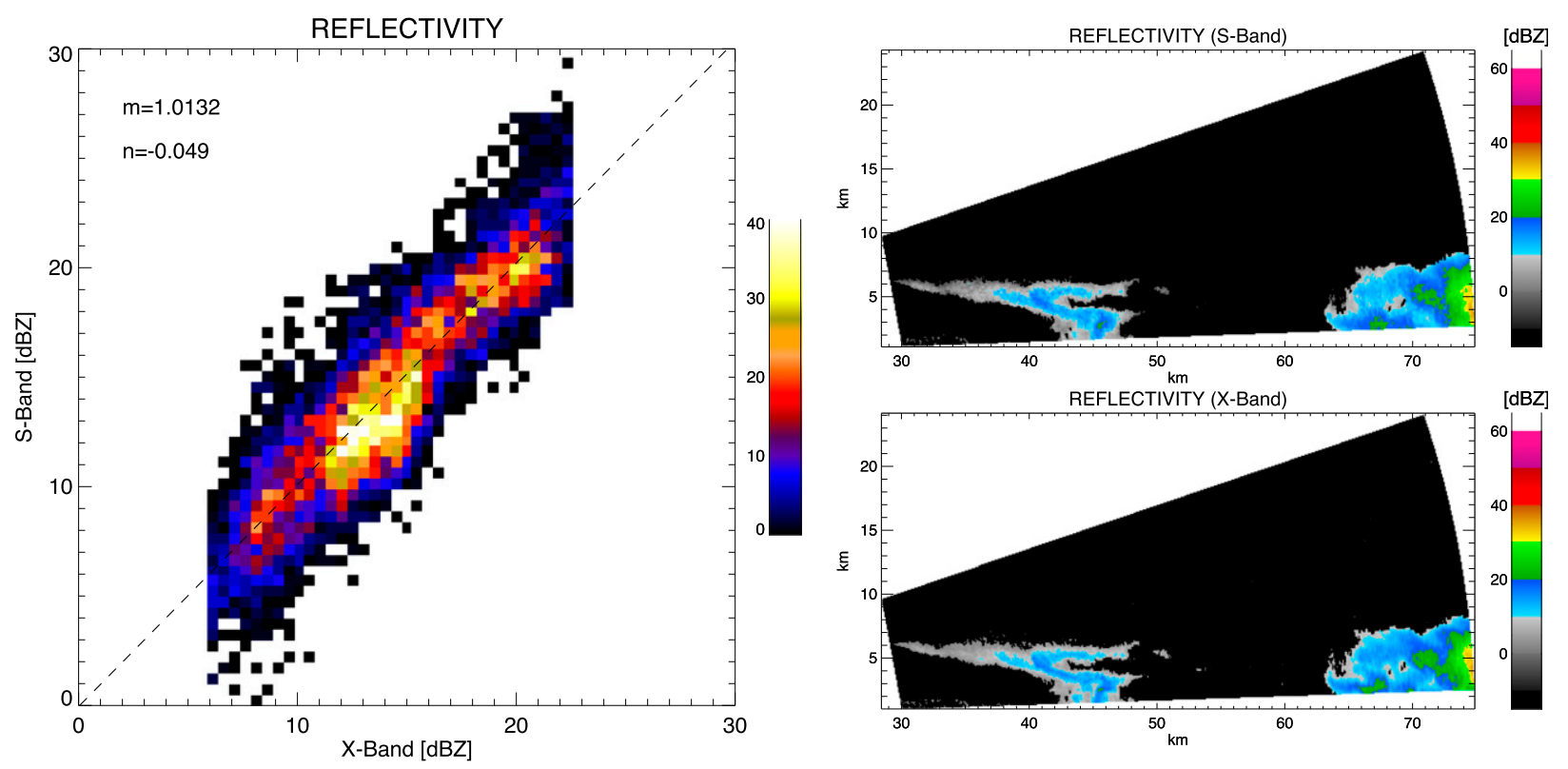

FIG. 4. (left) Example comparison of intrinsic reflectivity values (not corrected for attenuation) at $\mathrm{X}$ and $\mathrm{S}$ bands. (right) The data employed. These data may contain a mix of ice and water particles. In (a), the color points correspond to thresholded $2 \mathrm{D} Z$ histogram (see color scale indicating number of occurrences), and the dashed line is the resulting fit with slope $m$ and offset $n$. The fit shows that the two datasets are well correlated and unbiased, which is suitable for further joint processing such as attenuation correction. Data were collected on 3 Aug 2013 during the storm event presented in subsequent figures.

mismatch wherever possible. After that, verification (and correction if necessary) of the relative calibration between $\mathrm{X}$ - and S-band reflectivities is performed comparing an unattenuated portion of the storm (such as light rain and/ or ice in the storm near range side) at the two wavelengths as shown in Fig. 4.

The effect of the different attenuation correction strategies in the presence of a resonance scattering region is illustrated in Figs. 5 and 6, with data that is part of a PPI scan at $2.3^{\circ}$ in elevation, collected at 2240:49 UTC 3 August 2013 while severe thunderstorm activity affected several locations in northeastern Colorado. The CSU-CHILL radar was primarily collecting low-elevation-angle PPI sector scans, which captured a damaging hailstorm that moved across the southern portions of Greeley. A damage survey conducted by one of the authors turned up damage due to hail stones estimated at approximately $2-3 \mathrm{~cm}$ in diameter (roughly 1 in.).

In the first case (Fig. 5) a data ray of approximately $20 \mathrm{~km}$ in range has a strong region of enhanced Mie signal over a length of $5 \mathrm{~km}$ starting at around $10 \mathrm{~km}$ in range. In the uniform weight approach (Fig. 5a) one can see that the presence of the Mie signal creates a bias on the attenuation-corrected data-with $\mathrm{X}$ band crossing above $\mathrm{S}$-band values at approximately $15 \mathrm{~km}$ in range right after the Mie region. This is mitigated in Figs. 5b and 5c, using nonuniform weights and piecewise correction, respectively, where the attenuationcorrected reflectivity closely matches the reflectivity at S band after the region of enhanced Mie signal. Furthermore, the fact that the nonuniform weight and piecewise versions of the attenuation-corrected reflectivity closely match each other would suggest a constant $A(Z)$ relationship along the data ray (which in turn would imply that the joint underlying hydrometeor type and size distribution and associated extinction cross section is not changing). In the second case (Fig. 6) the uniform and nonuniform weight procedures give very similar results suggesting that the amount of Mie signal present does not create much of a bias. In both cases the attenuationcorrected X-band reflectivity starts diverging from the S-band reflectivity at around $8 \mathrm{~km}$ in range, whereas the piecewise approach yields an attenuation-corrected reflectivity that follows the $\mathrm{S}$ band more closely outside the resonance scattering region (from 10.5 to $15 \mathrm{~km}$ ). This could be indicative of a changing $A(Z)$ relationship in the data ray, which would imply a change in the underlying hydrometeor distribution and/or associated extinction cross sections.

Figure 7 shows an azimuthal sector scan to illustrate the Mie field obtained with the different instances of attenuation correction. Although it seems clear that the main area of enhanced resonance scattering is preserved in all cases, there are a few differences across the results. In the uniform-weight case (Fig. 7d) there is a large area 

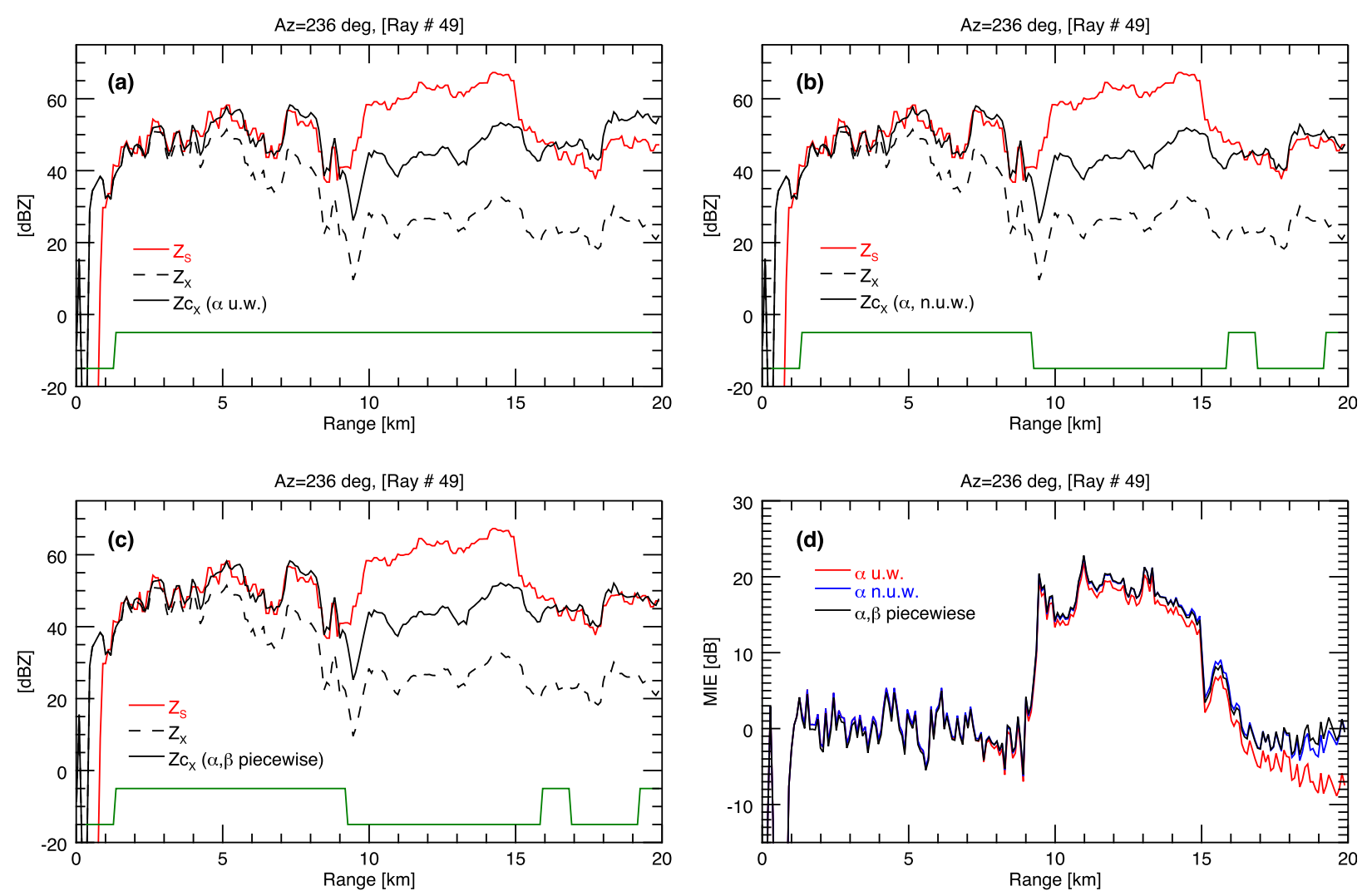

FIG. 5. Example of Mie signal retrieval using different instances of the attenuation-correction algorithm over a single ray. (a) Measured reflectivities at S and X bands and the resulting attenuation-corrected X-band signal using uniform weights. (b) Measured reflectivities at $S$ and $X$ bands and the resulting attenuation-corrected $X$-band signal using nonuniform weights. (c) Measured reflectivities at $\mathrm{S}$ and $\mathrm{X}$ bands and the resulting attenuation-corrected $\mathrm{X}$-band signal using a piecewise approach. (d) Mie signal resulting from the three different attenuation-correction approaches. One can see that the uniform-weight approach creates a bias on the retrieved results (see decreasing values starting at $15-\mathrm{km}$ range), whereas the nonuniform-weight and piecewise approaches yield very similar results, which may indicate a constant $A(Z)$ relationship along the data profile. Data were collected at 2240:49 UTC 3 Aug 2013, with an elevation angle (El) of $2.3^{\circ}$.

of negative values behind the main resonance scattering area due to its biasing effect. That is mitigated in the nonuniform weight case (Fig. 7f) and further reduced in the piecewise processing panel (Fig. 7h).

Since there may not be a priori knowledge of the $A(Z)$ relationship variability in the data being considered, and for simplicity we would like the Mie signal retrieval algorithm to not include any additional radar variables or products besides the reflectivity involved in attenuation correction, the previous results can be used to devise a Mie signal retrieval algorithm such as the one shown in Fig. 8. The algorithm computes attenuation correction in the three scenarios presented and the Mie signal is obtained from a combination/selection of the individual results, as follows:

1) An initial Mie signal retrieval [Eq. (9)] is performed using attenuation correction [Eqs. (3) and (4)] and uniform weights.
2) The obtained Mie signal is then used to create a set of nonuniform weights [as in Eq. (6), lowering the weight of regions where higher Mie values are detected] and to segment the data ray (piecewise ray truncation) in areas dominated by Rayleigh scattering and areas dominated by resonance scattering.

3) The nonuniform weights are used to create a new estimate of the Mie signal [Eq. (9)] using attenuation correction [Eqs. (3) and (4)] with the nonuniform weights.

4) Attenuation correction over segmented rays (as obtained in step 2) optimizing over both accumulated at start of segment and along segment pathintegrated attenuation in segments identified as Rayleigh is performed [Eq. (8)]. Attenuation correction in the resonance segments (constrained by adjacent Rayleigh region results) is then computed. 

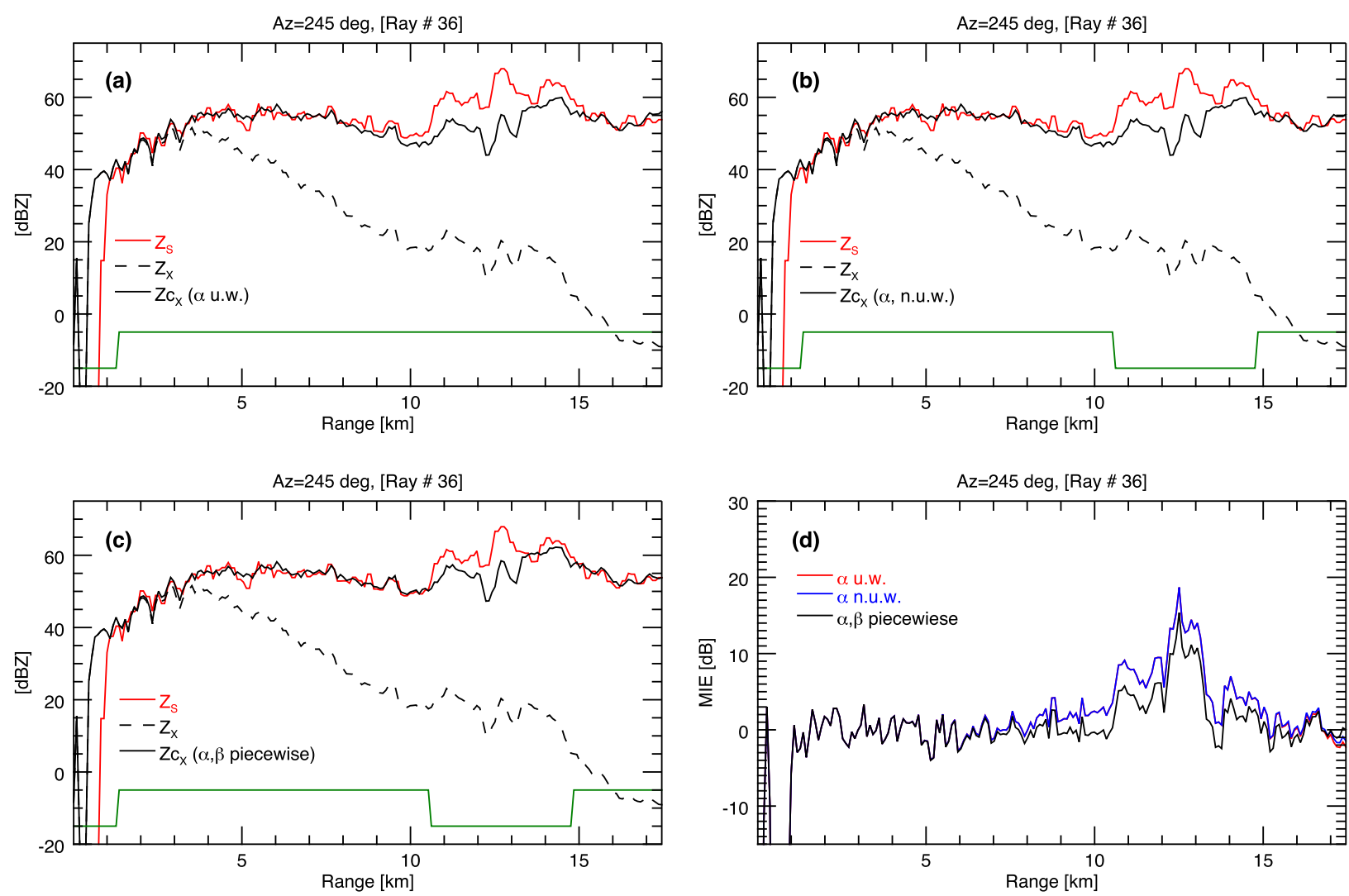

FIG. 6. Example of Mie signal retrieval using different instances of the attenuation correction algorithm over a single ray. (a) Measured reflectivities at $\mathrm{S}$ and $\mathrm{X}$ bands and the resulting attenuation-corrected $\mathrm{X}$-band signal using uniform weights. (b) Measured reflectivities at $\mathrm{S}$ and $\mathrm{X}$ bands and the resulting attenuation-corrected $\mathrm{X}$-band signal using nonuniform weights. (c) Measured reflectivities at $\mathrm{S}$ and $\mathrm{X}$ bands and the resulting attenuation-corrected X-band signal using a piecewise approach. (d) Mie signal resulting from the three different attenuation-correction approaches. One can see that the piecewise approach yields a smaller-magnitude Mie signal compared to the other approaches. In the uniform- and nonuniform-weight methods the attenuation-corrected X-band reflectivity starts diverging from the S-band reflectivity at around $8 \mathrm{~km}$ in range, whereas the piecewise approach yields an attenuation-corrected curve that more closely fits the S-band reflectivity outside the Mie region (from 10.5 to $15 \mathrm{~km}$ ). This could be indicative of a changing $A(Z)$ relationship in the different data profile regions. Data were collected at 2240:49 UTC 3 Aug 2013, with $\mathrm{El}=2.3^{\circ}$.

5) Final Mie signal is obtained from a weighted combination of the results obtained in steps 3 and 4 , minimizing the resulting Mie values in the Rayleigh scattering regions while maximizing them in the resonance regions.

\section{Mie signal and dual-polarization signatures}

The CSU-CHILL radar capability to generate a simultaneous dual-wavelength, dual-polarization collocated dataset enables comparing the Mie signal (retrieved from the dual-wavelength component) to the usual dual-polarization fields at $\mathrm{S}$ and $\mathrm{X}$ bands. This comparison is useful in understanding and validating the retrieved Mie signal, as it relates to hydrometeor size and composition, as also do the usual dual-polarization variables. As a simplified example, in a hail situation one may expect enhanced Mie signal and low $Z_{\mathrm{dr}}$, while in the presence of large drops one may expect enhanced Mie signal and enhanced $Z_{\mathrm{dr}}$. In this section we examine two different situations: in the first one the Mie signal information is collocated with other dual-polarization signatures, while in the second one it offers new information not readily inferable from the dual-polarization data fields.

Figure 9 shows an azimuth sector scan collected at $1.5^{\circ}$ elevation (the first scan in a four-elevation volume) through a hail-producing severe thunderstorm, showing $Z$ and $V$ at $\mathrm{S}$ band to illustrate the storm intensity and flow, the retrieved Mie signal, linear depolarization ratio (LDR) at $\mathrm{S}$ band (LDR is not available at $\mathrm{X}$ band owing to the radar simultaneous dual-polarization transmission and reception architecture at that wavelength) with overlaid Mie signal contours, $Z_{\mathrm{dr}}$ at $S$ band (which we consider easier to interpret than the $Z_{\mathrm{dr}}$ at $\mathrm{X}$ band, which would require differential attenuation correction) 

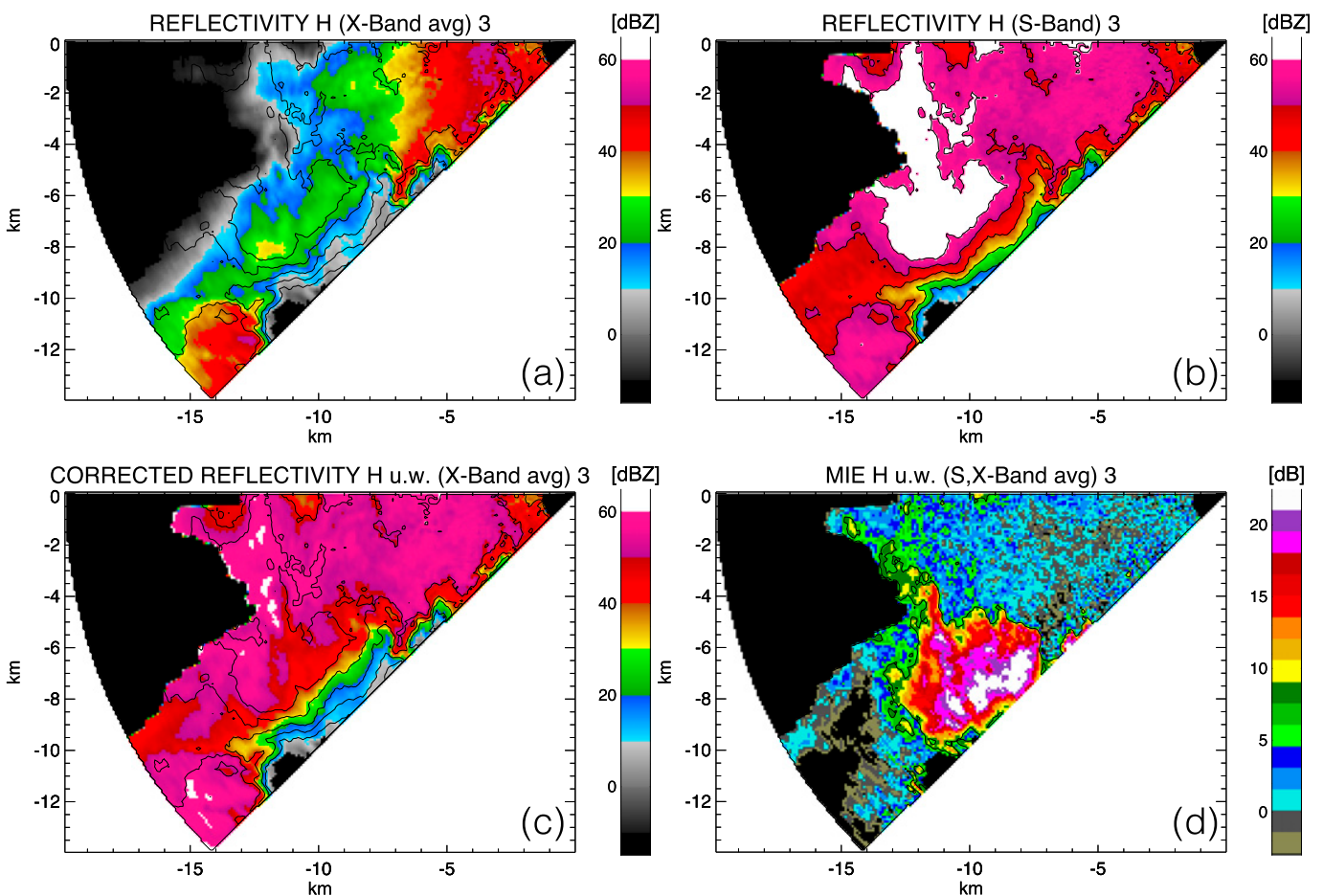

$[\mathrm{dB}]$
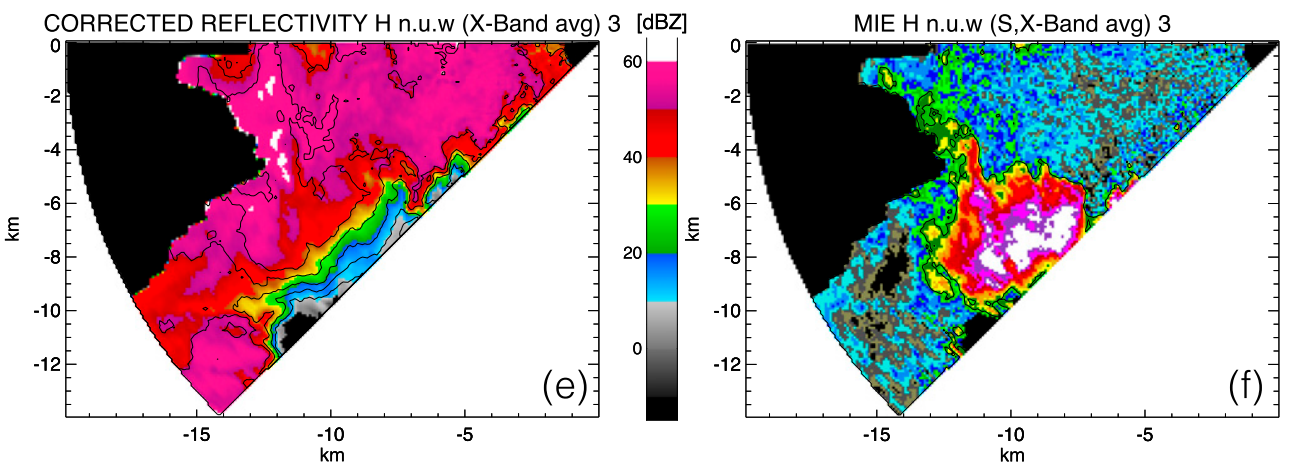

$[\mathrm{dB}]$
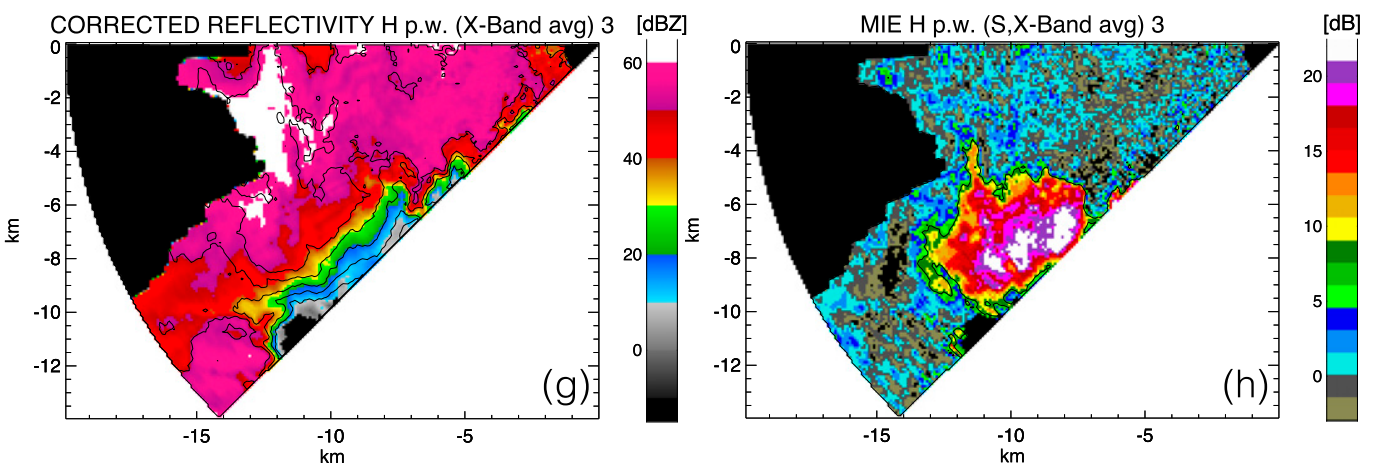

FIG. 7. Example of Mie signal retrieval using different instances of the attenuation correction algorithm over an azimuthal sector scan. (top) Measured $Z$ at (a) $\mathrm{X}$ and (b) $\mathrm{S}$ bands. (c),(e),(g) Attenuation-corrected $Z_{c}$ at $\mathrm{X}$ band and (d),(f),(g) the corresponding Mie signal for uniform-weight processing, nonuniform-weight processing, and piecewise processing, respectively. One can readily see that while the main region of enhanced Mie signal (white area centered at $-10 \mathrm{~km}$ west, $-8 \mathrm{~km}$ south of the radar location) is preserved in all cases, there a few differences across the images. In the uniform-weight processing in (d) there is a large area of negative values behind the main Mie signal due to its biasing effect. This is mitigated in the nonuniform-weight processing in (f) and further reduced in the piecewise processing in (h). Data were collected at 2240:49 UTC 3 Aug 2013, El $=2.3^{\circ}$. 


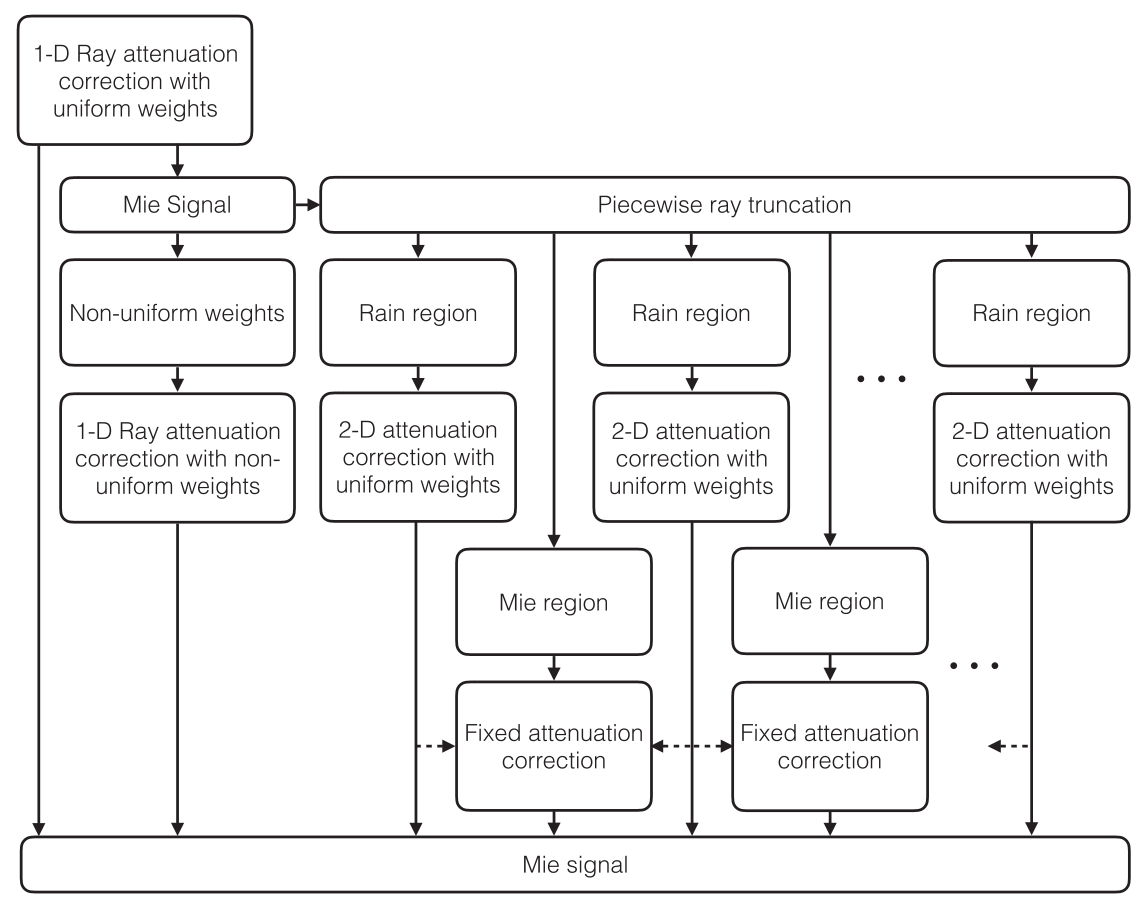

FIG. 8. Mie signal retrieval algorithm block diagram. An initial Mie retrieval is performed using uniform weights. The obtained Mie signal is then used to create a set of nonuniform weights (lowering the weight of regions where enhanced Mie signal is detected) and to segment the data ray in areas of Rayleigh scattering and resonance scattering. The nonuniform weights are used to create a new estimate of the Mie signal. Attenuation correction minimizing both accumulated at start of segment and along segment attenuation is performed for all segmented regions identified as Rayleigh scattering. Attenuation correction in the resonance scattering segments (constrained by adjacent Rayleigh region results) is then computed. The final Mie signal is obtained from combination/selection of nonuniformweight and piecewise results.

with overlaid Mie signal contours, and $\rho_{\mathrm{hv}}$ at $\mathrm{X}$ band (which is more sensitive to decorrelation effects due to hydrometeor shape variability at each polarization and liquid versus ice mix than its S-band counterpart) with overlaid Mie signal contours. The Mie signal shows an area of enhanced values roughly centered $8 \mathrm{~km}$ south and $12 \mathrm{~km}$ west of the radar location. Reflectivity $Z_{\mathrm{dr}}$ shows locally lower values in the area defined by the enhanced Mie signal contours, which also correspond to enhanced LDR as well as lower $\rho_{\mathrm{hv}}$. These signatures are consistent with one another and usually indicative of hail presence. Figures 10-12 show the subsequent antenna elevations $\left(1.7^{\circ}, 2.0^{\circ}\right.$, and $2.3^{\circ}$ ) collected in the same scan volume, showing an increase in the footprint and intensity of the combined hail signature as elevation increases, as well as a reach toward the edge of the storm indicative of an echo overhang and strong updraft (Miller et al. 1988). In Fig. 12 one can also see how the area encompassed by the enhanced Mie signal contour is roughly divided in a left area corresponding to lowest $Z_{\mathrm{dr}}$, highest
LDR, and low (but not lowest) $\rho_{\mathrm{hv}}$, consistent with hail as mentioned, and a right area of slightly higher $Z_{\mathrm{dr}}$, high (but not highest) LDR, and lowest $\rho_{\mathrm{hv}}$ where the hail may be either mixed with large raindrops or melting and covered with a layer of water (Knight 1986; Rasmussen and Heymsfield 1987; Aydin and Zhao 1990; Balakrishnan and Zrnić 1990; Herzegh and Jameson 1992; Ryzhkov et al. 2013a,b).

Figure 13 shows an RHI scan through a hail-producing thunderstorm, obtained at 2255:07 UTC 12 June 2017. Figure 13a shows $Z$ at $\mathrm{S}$ band, with an overhang of higher reflectivity values present aloft in the $24-27-\mathrm{km}$ range interval. This structure implies an updraft speed that is strong enough to suspend/loft large diameter hydrometeors-for example, during a flight through the weak echo region beneath an echo overhang in a severe thunderstorm in Montana, an armored research aircraft measured updrafts of $30-50 \mathrm{~m} \mathrm{~s}^{-1}$ (Musil et al. 1986). The aircraft also encountered hail up to $4 \mathrm{~cm}$ in diameter just to the west of the weak echo region. Figure 13b shows the Mie signal, with an enhanced area 

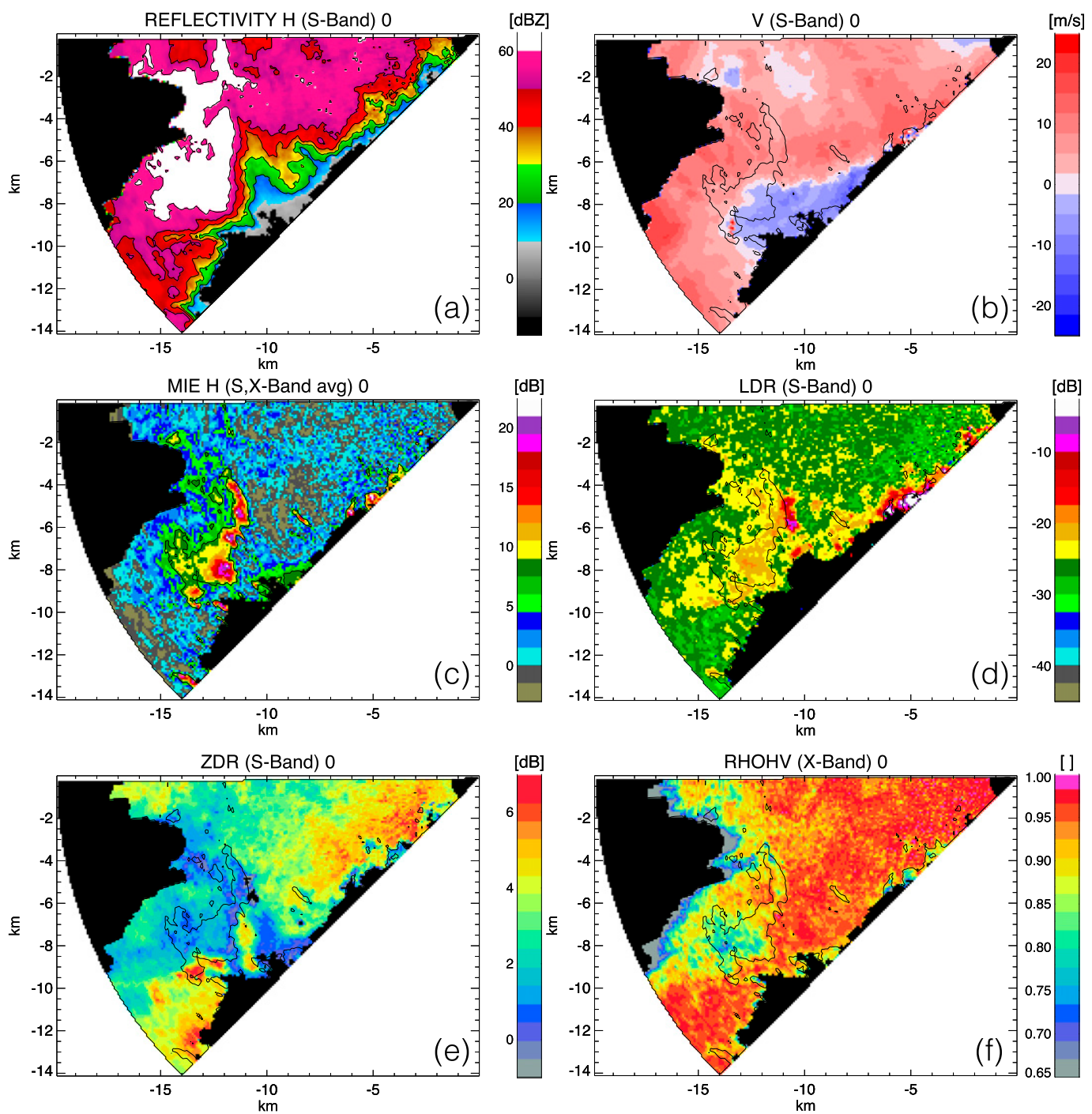

FIG. 9. Comparison of Mie signal with dual-polarization features in a thunderstorm. Data were collected at 2239:29 UTC 3 Aug 2013, PPI scan at $\mathrm{El}=1.5^{\circ}$, corresponding to sweep 1 of 4 in the collected volume. (top) Measured (a) $Z$ and (B) $V$ at S band. (c) Mie signal, with a well-defined area of enhanced values (above $10 \mathrm{~dB}$ ) collocated with locally (d) higher LDR (above $-25 \mathrm{~dB}$ ) and (e) lower $Z_{\mathrm{dr}}$ (below $1 \mathrm{~dB}$ ) at $\mathrm{S}$ band, as well as (f) lower $\rho_{\mathrm{hv}}$ (between 0.75 and 0.90 ) at $\mathrm{X}$ band), indicative of hail presence.

aloft roughly corresponding to the reflectivity overhang and extending into the downdraft area. Figure 13e shows $Z_{\mathrm{dr}}$ at $\mathrm{S}$ band with overlaid Mie signal contours. The positive values associated with the inflow are clearly distinguishable and create a well-defined border with the Mie contour. Figure $13 \mathrm{c}$ shows $\phi_{\mathrm{dp}}$ at $\mathrm{X}$ band. The increasing values corresponding with the inflow are also distinguishable, together with a clear bump (at approximately $29 \mathrm{~km}$ in range and $3 \mathrm{~km}$ in height) due to differential phase shift upon backscatter and consistent with the presence of hail (Aydin et al. 1991; Trömel et al. 2013). This bump is collocated with a large dip in $\rho_{\mathrm{hv}}$ at $\mathrm{X}$ band (Fig. 13f), also consistent with correlation reduction due to resonance scattering (Balakrishnan and Zrnić 1990), and enhanced LDR at S band (Fig. 13d), which in turn are inside and toward the front area of the Mie signal contour. This is consistent with the expected variation from positive $Z_{\mathrm{dr}}$ related to raindrop size sorting in the updraft to the low $Z_{\mathrm{dr}}$ and high reflectivity coexistence that is typical in the hail-dominated area of the lower-level main echo core (Kumjian and Ryzhkov 2008). Figure 14 shows a detailed comparison of range profiles along the data ray at an antenna elevation angle of $5.0^{\circ}$. The enhanced Mie signal encompasses the range of the $\rho_{\mathrm{hv}}$ dip, which goes down to a value of $\sim 0.45$ where $\phi_{\mathrm{dp}}$ exhibits a local 

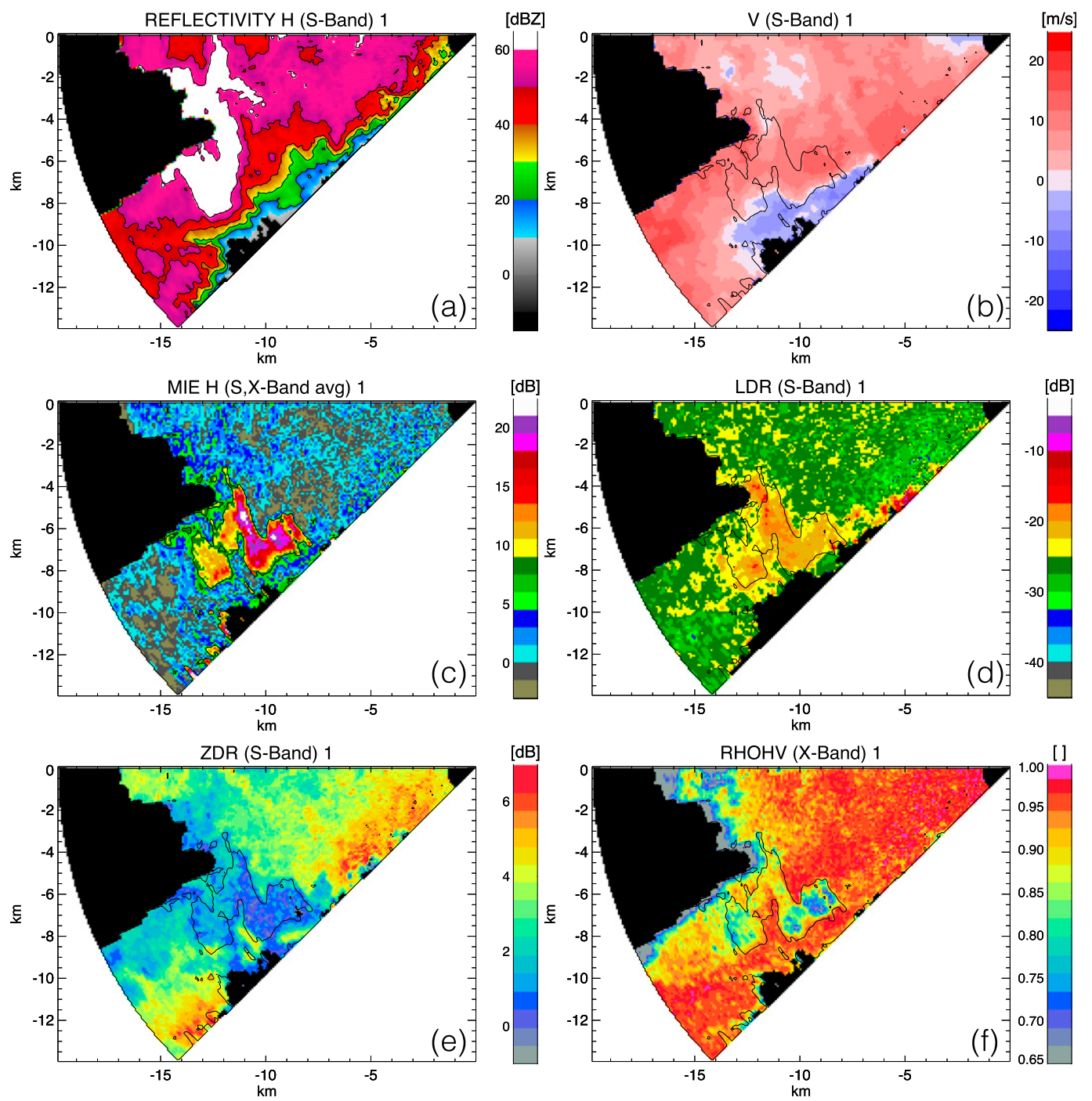

FIG. 10. As in Fig. 9, but for a subsequent scan. Data were collected at 2239:56 UTC 3 Aug 2013, PPI scan at El = $1.7^{\circ}$, corresponding to sweep 2 of 4 in collected volume.

increase of $\sim 30^{\circ}$. It is worth noting that the $\phi_{\mathrm{dp}}$ values in the $26-28-\mathrm{km}$ range are affected by differential phase shift upon backscatter because of the large drops present in the inflow (see corresponding $Z_{\mathrm{dr}}$ values in excess of $5 \mathrm{~dB}$ ), and those large drops have an expected small negative Mie value as shown in the corresponding plots (also, see Fig. 2 in the 5-9-mm region).

A severe thunderstorm observed during the early UTC hours of 30 July 2016 produced a swath of hail reports in the 3.5-5-cm-diameter range in the northwest azimuth quadrant of the radar near the time of interest ( $\sim 0033$ UTC). Figures 15 and 16 show contiguous RHI scans (at $328^{\circ}$ and $330^{\circ}$ in azimuth) obtained through this severe thunderstorm extending out to $40 \mathrm{~km}$ in range, showing a strong updraft and descending reflectivity core. The panels in the figures show $Z$ at $\mathrm{S}$ band, Mie signal at $\mathrm{X}$ band, Doppler velocity at $\mathrm{S}$ band with overlaid Mie signal contours, LDR at $S$ band with overlaid Mie signal contours, $Z_{\mathrm{dr}}$ at $S$ band with overlaid Mie signal contours, and $\rho_{\mathrm{hv}}$ at $\mathrm{X}$ band with overlaid Mie signal contours. Both RHI scans show a well-defined region of higher (above $15 \mathrm{~dB}$ ) Mie signal values starting approximately at $25 \mathrm{~km}$ in range and $5 \mathrm{~km}$ in height and reaching the ground approximately at $28 \mathrm{~km}$ in range. The area defined by this Mie signal contour is collocated with enhanced LDR, low $Z_{\mathrm{dr}}$, and low $\rho_{\mathrm{hv}}$, all indicative of a descending hail core. However, above that region, the Mie signal exhibits another region of enhanced values (fluctuating around the $10-\mathrm{dB}$ mark) located upstream of the descending hail core, above the Doppler velocity indicated updraft, and with no corresponding signatures in the dual-polarization fields as it is located 

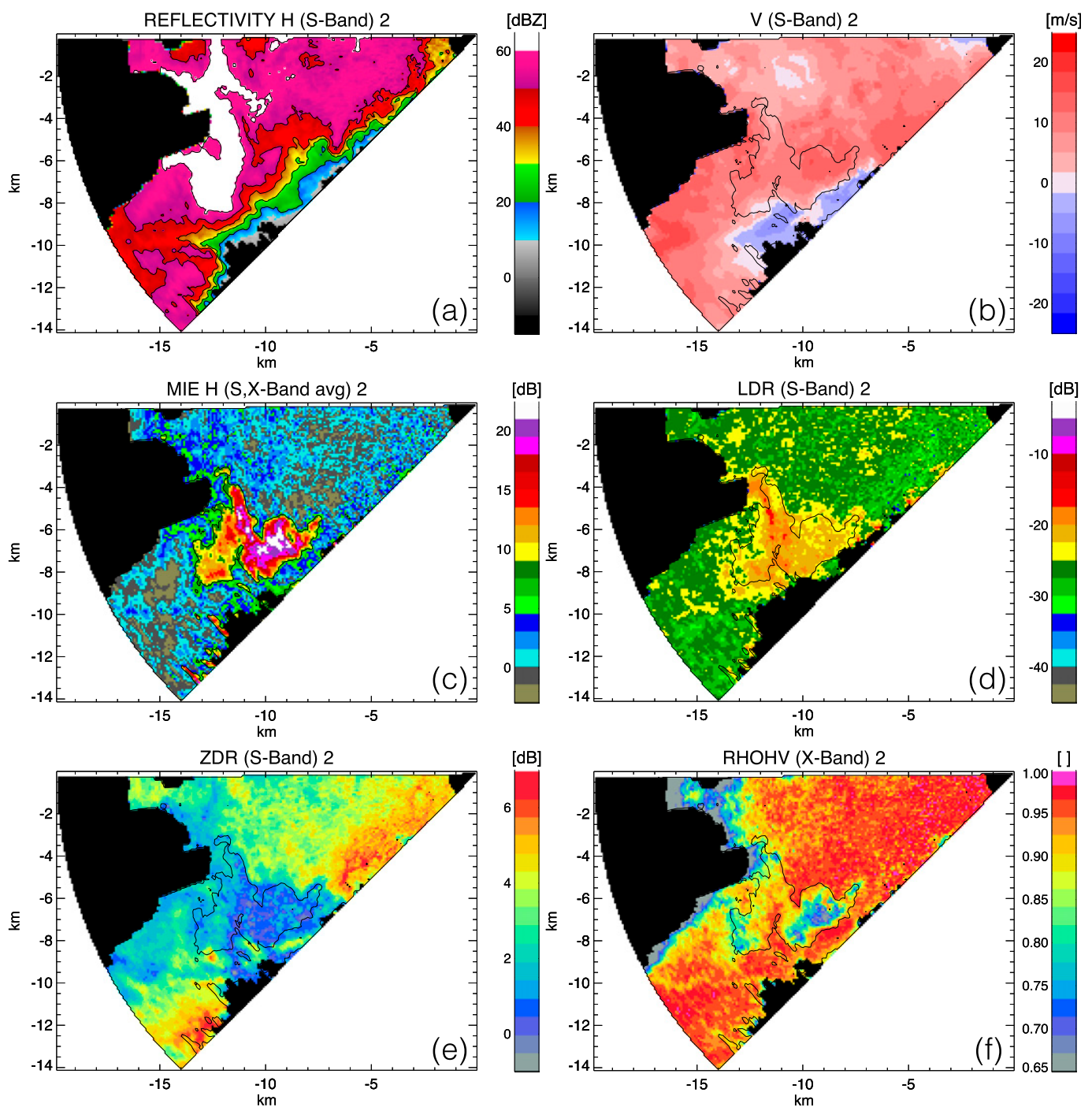

FIG. 11. As in Fig. 9, but for a subsequent scan. Data were collected at 2240:24 UTC 3 Aug 2013, PPI scan at El = $2.0^{\circ}$, corresponding to sweep 3 of 4 in collected volume.

in the ice particle portion of the storm. This is consistent with the presence of ice particles of at least the $\sim 1 \mathrm{~cm}$ in diameter associated with detectable dual-wavelength hail signals (Herzegh and Jameson 1992). The location of this Mie signal was also found just above the weak echo "vault" as depicted in the RHI scan. This location has been found to be an important hail growth region (Conway and Zrnić 1993), possibly showing the embryos for the hailstones that reach the ground. The dualpolarization variables in that region would be muted because of the presence of entirely frozen particles (with relatively low refractive index) that are likely quasispherical and wobbling. This is further explored in Fig. 17, showing data rays following a line along the downdraft path (the line is shown overlaid on the data panels in Figs. 15 and 16). The data rays are divided in three regions along the radar elevation angle: at the highest elevation angles (above $30^{\circ}$, corresponding to the top portion of the storm) LDR, $Z_{\mathrm{dr}}$, and $\rho_{\mathrm{hv}}$ are consistent with the presence of ice particles while the Mie signal is mostly flat around $0 \mathrm{~dB}$ as expected from small particles. Below that region (between $18^{\circ}$ and $30^{\circ}$ in antenna elevation angle) the dual-polarization variables are still consistent with the presence of ice particles ( $Z_{\mathrm{dr}}$ closely around $0 \mathrm{~dB}$, high $\rho_{\mathrm{hv}}$, and low LDR) but the Mie signal starts an increasing trend indicative of the larger signal contribution from hailstones large enough to generate appreciable resonance scattering effectspossibly hailstone embryos as previously discussed. In the lower antenna angles (below $18^{\circ}$ in elevation) the Mie signal continues to increase while $\rho_{\mathrm{hv}}$ decreases, LDR enhances, and $Z_{\mathrm{dr}}$ fluctuates around zero except at 

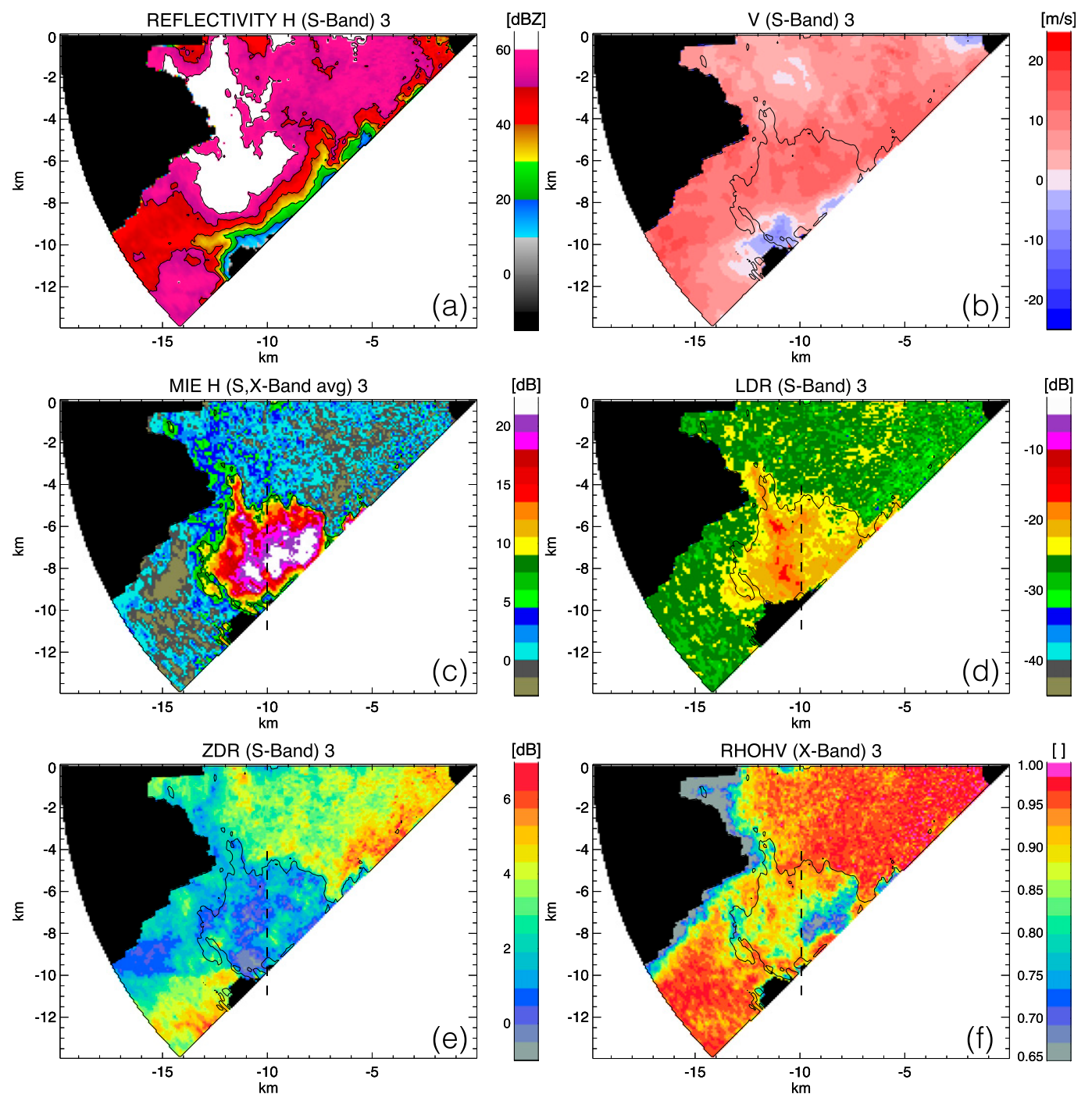

FIG. 12. As in Fig. 9, but for a subsequent scan. Data were collected at 2240:49 UTC 3 Aug 2013, PPI scan at El = $2.3^{\circ}$, corresponding to sweep 4 of 4 in collected volume. Figures $9-12$ show vertical continuity and spatial coherence for the Mie signal and dual-polarization signatures across the different elevation scans.

the lowest elevation angles where it increases some, indicating the presence of hail and hail-rain mix. The appearance of an enhanced Mie signal region (responding to larger-size particles) in the ice portion of the storm (whereas the dual-polarization variables that typically respond to organized scatterer shape are muted in the presence of quasi-spherical and wobbling frozen particles) indicates the potential of the retrieved Mie signal to diagnose areas of hail growth aloft. It is worth noting that in general one should expect reduced dual-polarization values at antenna elevations above $20^{\circ}-30^{\circ}$ because of the relative angle between the radar beam and observed hydrometeors (e.g., Bringi and Chandrasekar 2001), and that no correction for that effect is attempted here. However, one should not expect such reduction in the retrieved Mie signal, as it is obtained from the difference in reflectivity measurements that are affected equally by the beamscatterer geometry.

\section{Mie signal and hail reports}

Hail reports can be used to obtain a first-order validation of the retrieved Mie signal in the radar data. Overlapping the location of hail reports with the retrieved Mie signal field gives an indication of spatial correlation between reported hail locations and radarderived Mie signal locations. However, hail reports (as well as other types of severe weather reports such as damaging winds; Trapp et al. 2006) can be sparse in 

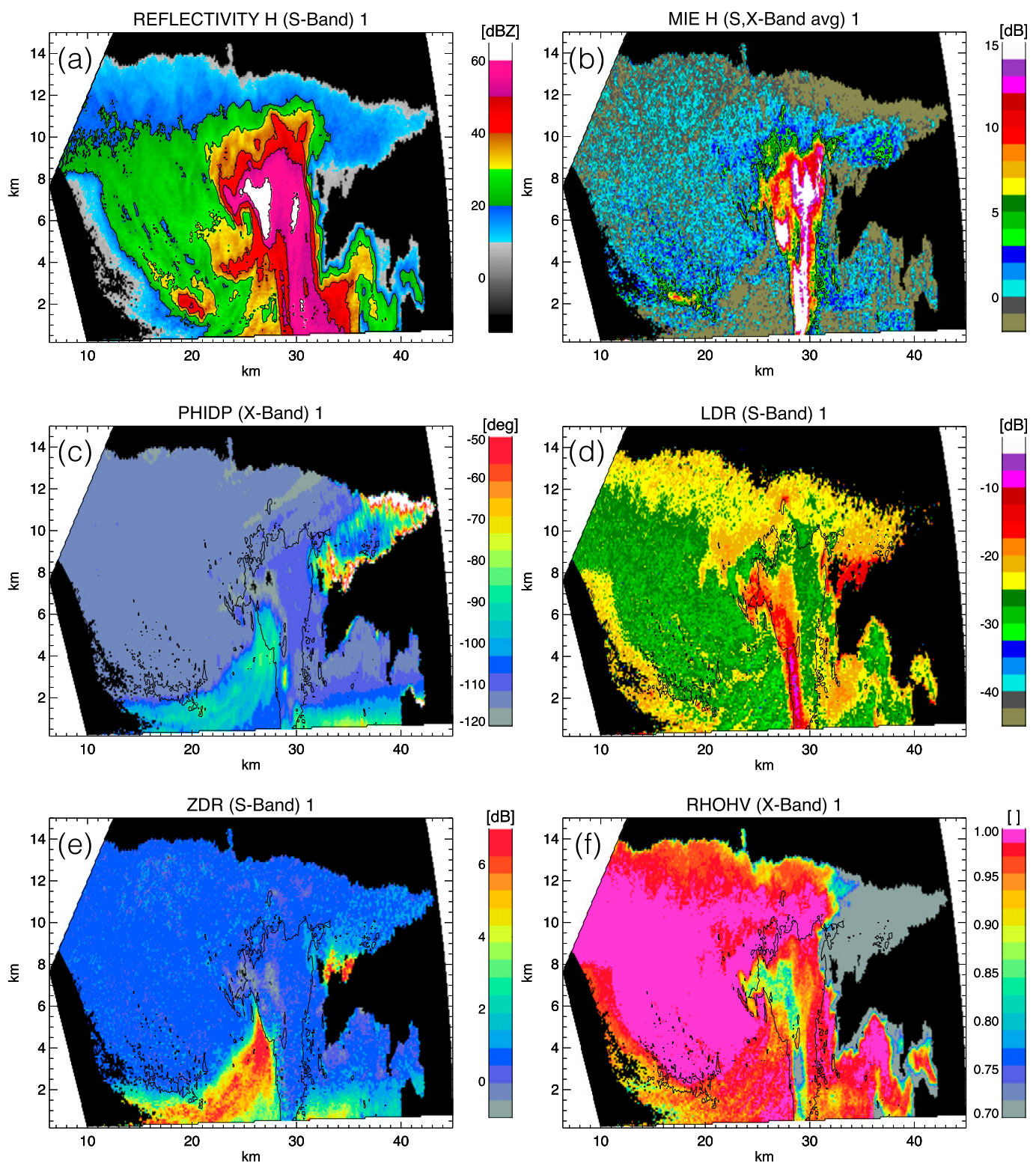

FIG. 13. Comparison of Mie signal with dual-polarization features in a thunderstorm. Data were collected at 2100:36 UTC 12 Jun 2017, RHI scan at azimuth $(\mathrm{Az})=305^{\circ}$, corresponding to sweep 1 of 2 in collected volume. (a) Measured $Z$ at S band and (b) the obtained Mie signal with an area in excess of $10 \mathrm{~dB}$ collocated with the reflectivity core. (c) $\phi_{\mathrm{dp}}$ at $\mathrm{X}$ band, showing a steep bump (in excess of $30^{\circ}$, located at $29 \mathrm{~km}$ in range and $3 \mathrm{~km}$ in height and due to a differential phase shift upon backscatter) collocated with (d) higher LDR (above $-20 \mathrm{~dB}$ ) and (e) lower $Z_{\mathrm{dr}}$ (close to $0 \mathrm{~dB}$ ) at $\mathrm{S}$ band, as well as (f) lower $\rho_{\mathrm{hv}}$ at $\mathrm{X}$ band (below 0.85 ), indicative of hail presence. The small echo area near 33-km range and $8-\mathrm{km}$ height on the underside of the anvil that contains highly positive S-band $Z_{\mathrm{dr}}$ and noisy $\mathrm{X}$-band $\phi_{\mathrm{dp}}$ values way above its surroundings is an artifact of three body scattering.

space and time (typically confined to regions with human presence) and prone to information loss due to after-the-fact reporting and imprecise time and size determination. To try mitigating some of these issues and obtain more meaningful information, the hail reports for the four storm events (4 June 2015, 3 June 2015,
24 May 2016, and 30 July 2016) presented here are aggregated in time and overlapped over the retrieved Mie signal field maximum value for the same time period (i.e., we assume that the reported hail size at a given location is paired with the maximum Mie value over that location for a given storm duration), as shown in 

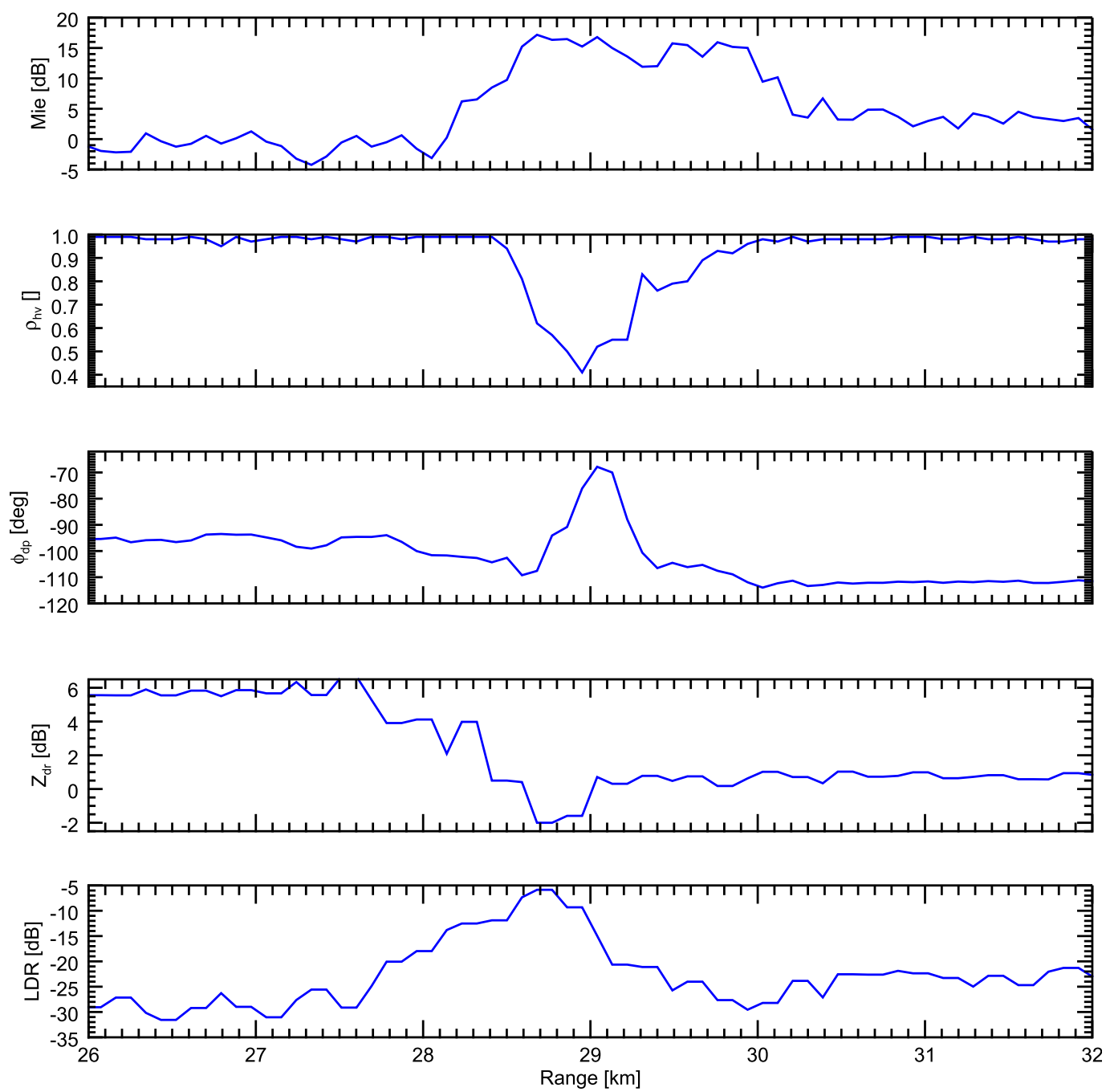

FIG. 14. Comparison of range profiles along the data ray at $\mathrm{El}=5.9^{\circ}$ for the dataset shown in Fig. 13. The range of enhanced Mie signal is well aligned with the dip in $\rho_{\mathrm{hv}}$ at $\mathrm{X}$ band and the enhanced $\phi_{\mathrm{dp}}$ at $\mathrm{X}$ band and LDR at $S$ band.

Fig. 18. For all of these cases, a review of the radar echo histories confirmed that only a single storm passage was responsible for the reported hail deposition. Figures 18a, $18 \mathrm{c}, 18 \mathrm{e}$, and $18 \mathrm{~g}$ show overlapping hail report locations and retrieved Mie signal maximum for the four different hail-producing storm events. For the four cases of hail size presented here, the basic hail size data came from observations collected in the NOAA Storm Predication Center's Storm Reports and from the volunteer observations compiled by the Community Collaborative Rain, Hail and Snow Network (CoCoRaHS). Additionally, one of the authors interviewed local residents in the areas affected by the two 2016 storm cases. In all four cases one can see how the hail report locations cluster around areas of enhanced Mie signal, showing the potential for the reflectivity-only method used to retrieve
Mie signal to indicate possible hail areas, in line with previous findings (Atlas and Ludlam 1961; Eccles and Atlas 1973; Jameson and Srivastava 1978; Jameson and Heymsfield 1980; Bringi et al. 1986a; Tuttle et al. 1989; Herzegh and Jameson 1992). Additionally, corresponding scatterplots of reported hail size versus maximum Mie signal for the reported locations are shown in Figs. 18b, 18d, 18f, and 18h, together with their corresponding linear regression fit. All cases show weak to moderate linear regression correlation coefficient values between hail size and maximum Mie signal (with $r$ values of $0.33,0.59,0.54$, and 0.60 ), but no unique relationship (i.e., different intercept slope and intercept points for every case). This may be attributed to variability in the specific hail characteristics (such as size, shape, temperature, and ice vs water proportion; 

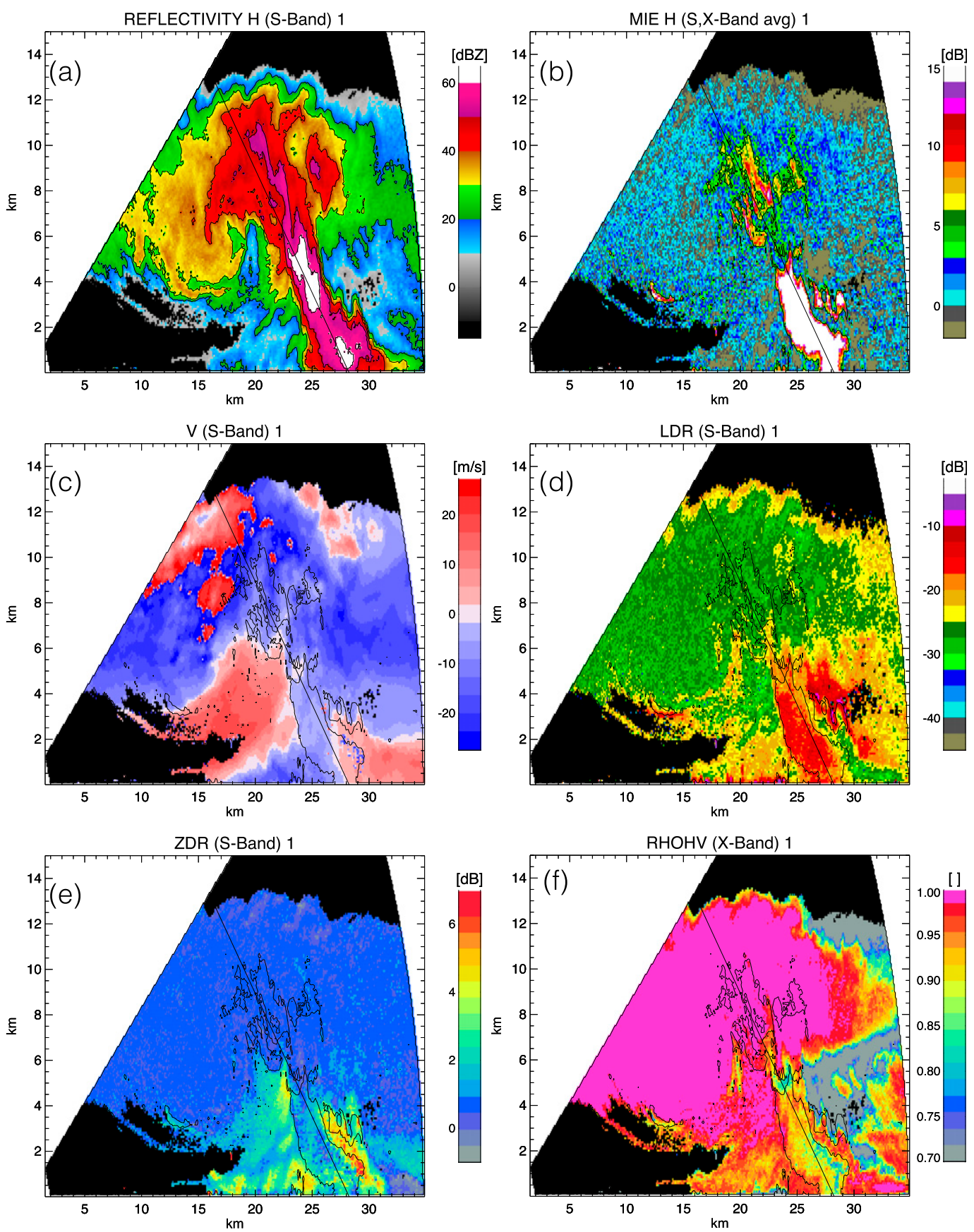

FIG. 15. Comparison of Mie signal with dual-polarization features in a thunderstorm. Data were collected at 0032: 59 UTC 30 Jul 2016, RHI scan at $\mathrm{Az}=328^{\circ}$, corresponding to sweep 1 of 4 in collected volume. (a) Measured $Z$ at $\mathrm{S}$ band and (b) the resulting Mie signal at X band. (c) Doppler velocity, (d) LDR, and (e) $Z_{\mathrm{dr}}$ at S band and (f) $\rho_{\mathrm{hv}}$ at X band. One can see a well-defined region of large Mie values $(>15 \mathrm{~dB})$ starting roughly at $25 \mathrm{~km}$ in range and $5 \mathrm{~km}$ in height, descending to the ground at roughly $28 \mathrm{~km}$ in range. This area is collocated with enhanced (above $-20 \mathrm{~dB}$ ) LDR, low (around $1 \mathrm{~dB}) Z_{\mathrm{dr}}$, and low (around 0.9) $\rho_{\mathrm{hv}}$ values, all indicative of a descending hail core. Above that region, the Mie signal panel reveals an area of potential hail embryo growth. 

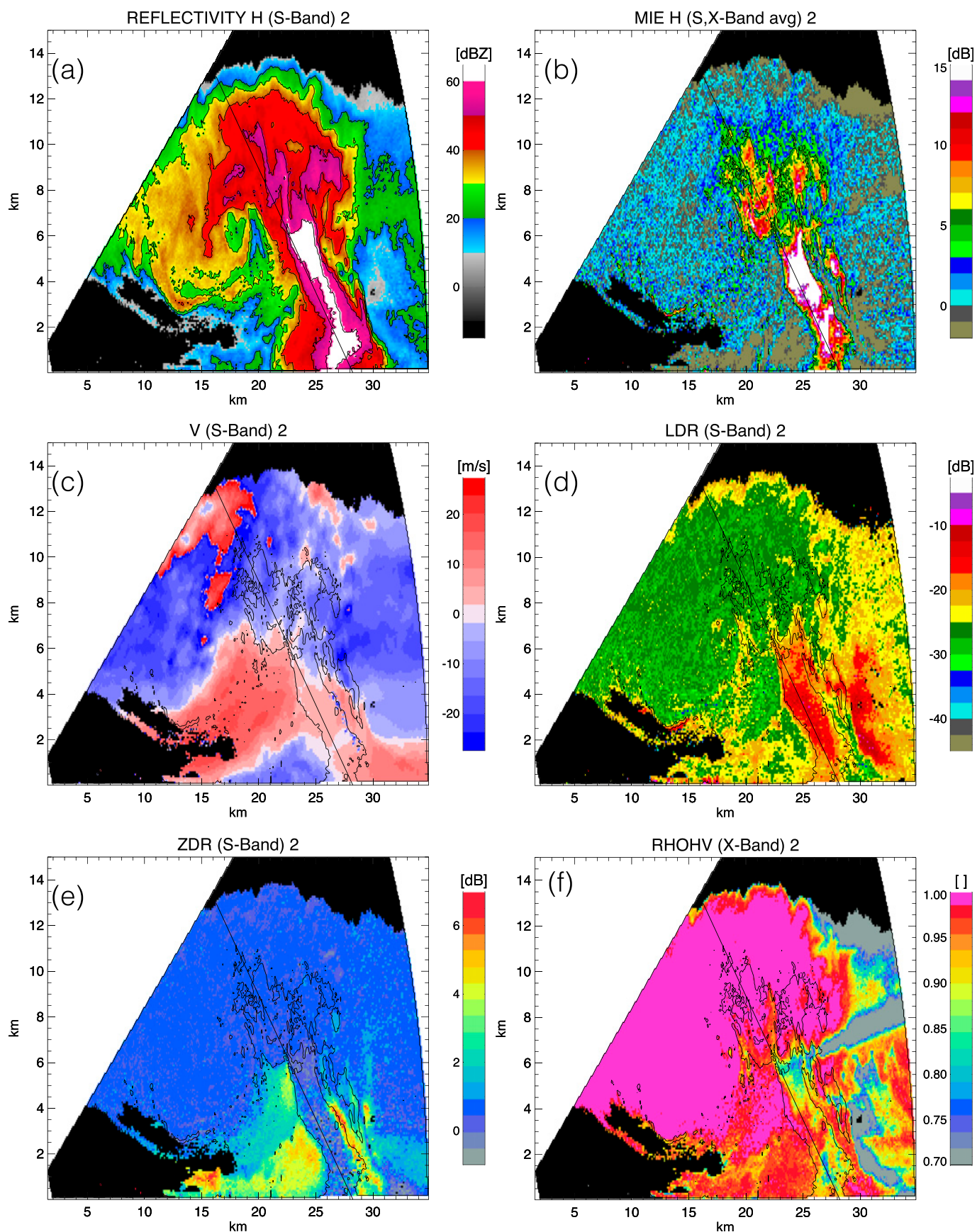

FIG. 16. As in Fig. 15, but for a subsequent scan. Data were collected at 0032:59 UTC 30 Jul 2016, RHI scan at Az = $330^{\circ}$, corresponding to sweep 2 of 4 in collected volume.

Jameson and Srivastava 1978) and may potentially be of use in determining those characteristics.

\section{Summary and conclusions}

This paper has introduced a new method to retrieve a Mie signal for a scanning S- and X-band dualwavelength radar, using the reflectivity-only attenuation correction procedure introduced in Junyent and Chandrasekar (2016) to establish the areas where the attenuation-corrected X-band reflectivity differs from the measured S-band reflectivity because of resonance effects. This method does not involve any dualpolarization variables at any of the wavelengths (i.e., can be implemented on single-polarization, dual-wavelength collocated datasets) and therefore is not affected 


\section{Mie}

$\rho_{\mathrm{hv}}$

$Z_{\mathrm{dr}}$

LDR
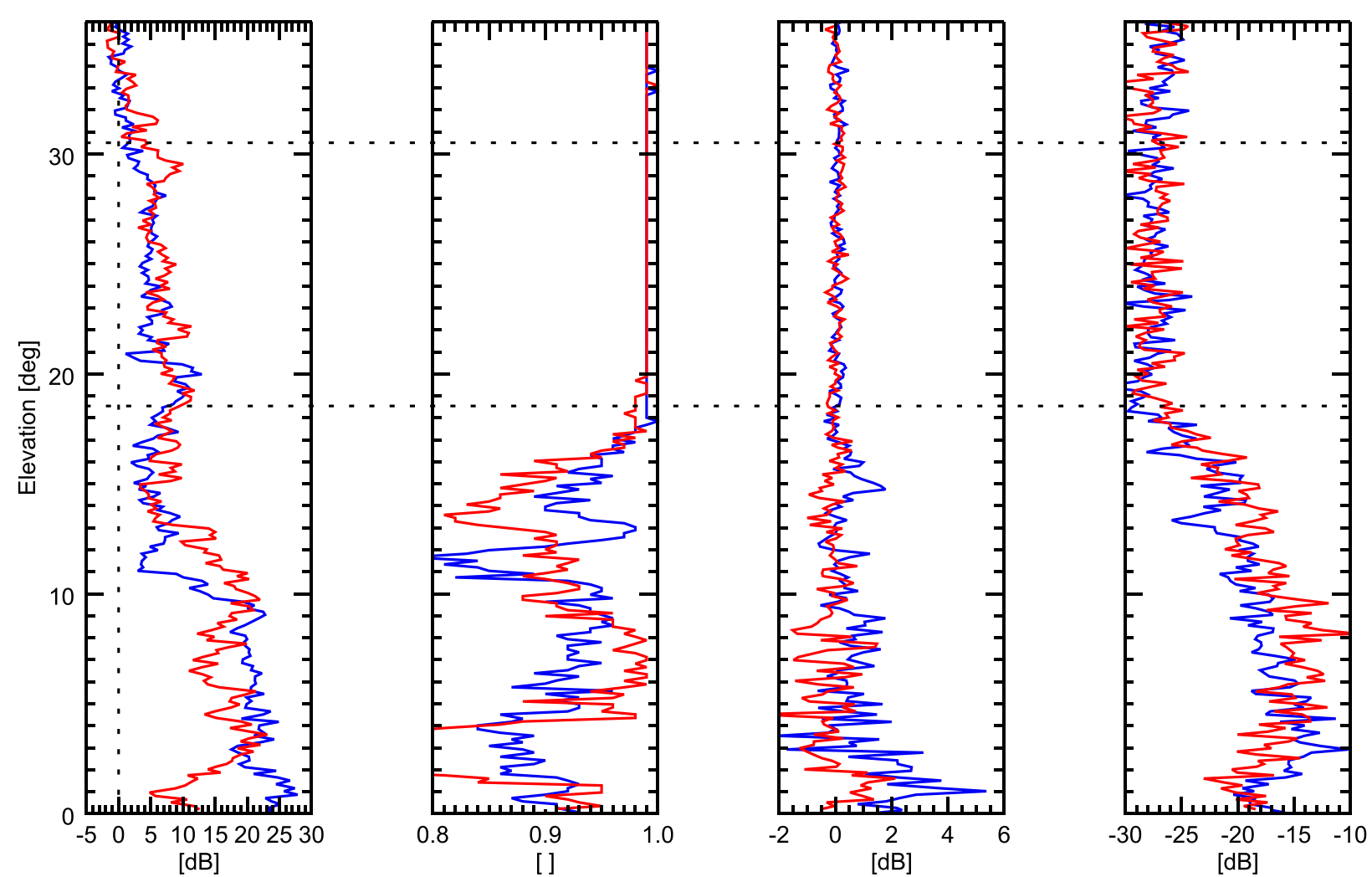

FIG. 17. Comparison of Mie signal with dual-polarization features (X-band $\rho_{\mathrm{hv}}$ and S-band $Z_{\mathrm{dr}}$ and LDR) along a line defined by the storm downdraft (as shown in previous RHI figures collected at 0032:59 UTC $30 \mathrm{Jul} 2016$ ). At higher antenna elevation angles ( $>30^{\circ}$, corresponding to the top part of the storm) low LDR, near-zero $Z_{\mathrm{dr}}$, and high $\rho_{\mathrm{hv}}$ are consistent with the presence of ice particles, while the Mie signal is mostly flat around zero, as expected from small particles. Below that region (from $18^{\circ}$ to $30^{\circ}$ antenna elevation) the dualpolarization variables are still consistent with the presence of ice, but the Mie signal starts an increasing trend, indicative of larger-size particles, possibly hailstone embryos. In the lower antenna elevation angles $\left(<18^{\circ}\right)$ the Mie signal continues to increase, reaching $15 \mathrm{~dB}$ while $\rho_{\mathrm{hv}}$ decreases around 0.9 , depolarization enhances up to $-15 \mathrm{~dB}$, and $Z_{\mathrm{dr}}$ fluctuates around zero, indicating the presence of hail and a hail-rain mix.

by the relative geometry of the radar and the scatterers in the resolution volume. Moreover, the retrieved Mie signal is obtained directly from the difference of S-band reflectivity and attenuation-corrected X-band reflectivity, and not from range-derivative processing of the dual wavelength ratio as in much of the literature.

The presented Mie signal retrieval method is applied to different storm events, first comparing the obtained Mie field with collocated dual-polarization fields leveraging the CSU-CHILL's dual-wavelength and dualpolarization capability. The studied cases show that where the obtained higher Mie values may be indicative of established hailstones, the dual-polarization fields show well-collocated signatures (low differential reflectivity, low copolar correlation coefficient, enhanced linear depolarization ratio) that reinforce the obtained Mie signal validity. In other situations where the dualpolarization data may be muted such as high elevation scans in the ice portion of the storm, the retrieved Mie signal may bring new information as in the case of larger ice particles possibly developing into hailstones.

The presented Mie retrieval method is also used to compare reported hailstone size and location with maximum Mie values for a storm duration, showing that for all studied cases the maximum Mie values for the storm duration are well collocated with the reported hail locations. A linear fit of the obtained maximum Mie value versus reported hail size shows up to moderate linear correlation coefficient values but no unique relationship. This may be attributed to the variability of the hail characteristics, and the Mie value together with other information may be of use in determining those characteristics.

Acknowledgments. This material is based upon work supported by the National Science Foundation under Cooperative Agreement AGS 1138116. 

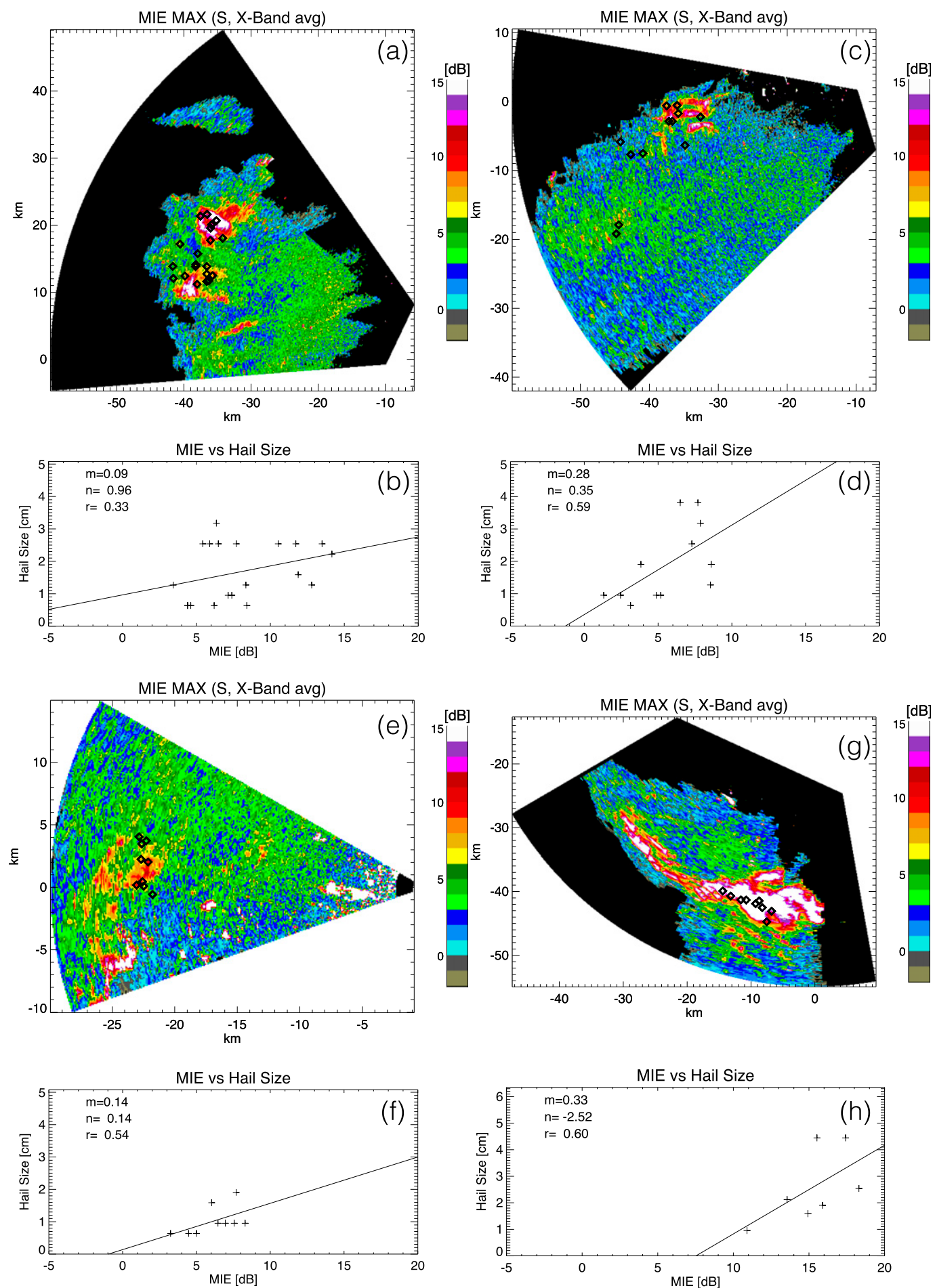

FIG. 18. Comparison of Mie signals and hail reports. (a),(c),(e),(g) Maximum Mie signal value observed for all the sweeps collected during each of the four hail events, with the locations of confirmed hail reports overlaid as black diamonds. (b),(d),(f),(h) The corresponding scatterplots between the reported hail size and the retrieved Mie signal maximum for the reported locations. Data were collected on (a),(b) $4 \mathrm{Jun} 2015$ as PPI scans at El $=1.8^{\circ}$; (c),(d) 3 Jun 2015 as PPI scans at $\mathrm{El}=1.5^{\circ}$; (e),(f) 24 May 2016 as PPI scans at $\mathrm{El}=1.8^{\circ}$; and (g),(h) $30 \mathrm{Jul} 2016$ as PPI scans at $\mathrm{El}=1.8^{\circ}$. 


\section{APPENDIX}

\section{Procedure to Synthesize Matching Beams}

By design, the 3-dB beamwidth of the CSU-CHILL radar at $\mathrm{S}$ band is $1^{\circ}$, which is roughly 3 times that of the $\mathrm{X}$-band component at $0.3^{\circ}$. To minimize the potential occurrence of artifacts due to beam mismatch side effects (Rinehart and Tuttle 1982), the data presented throughout this paper have been postprocessed to synthesize a beam resolution at $\mathrm{X}$ band that matches that of the measurement at $\mathrm{S}$ band in the antenna scanning plane dimension (azimuth for PPI type scans, elevation for RHI type scans) according to

$$
\begin{aligned}
& P^{\mathrm{AVG}}=\sum_{n} P[n], \\
& \phi_{\mathrm{dp}}^{\mathrm{AVG}}=\frac{180^{\circ}}{\pi} \tan ^{-1}\left\{\frac{\sum_{n} P[n] \sin \left(\frac{\pi}{180^{\circ}} \phi_{\mathrm{dp}}[n]\right)}{\sum_{n} P[n] \cos \left(\frac{\pi}{180^{\circ}} \phi_{\mathrm{dp}}[n]\right)}\right\} .
\end{aligned}
$$

The index $n$ is used to indicate the data rays at $\mathrm{X}$ band that fall inside the integration limits of a data ray at $\mathrm{S}$ band, $P$ is for signal power (from which reflectivity and signal-to-noise ratio can be obtained), and $\phi_{\mathrm{dp}}$ is differential propagation phase (from which specific phase $K_{\mathrm{dp}}$ can be obtained).

\section{REFERENCES}

Atlas, D., and F. Ludlam, 1961: Multi-wavelength radar reflectivity of hailstorms. Quart. J. Roy. Meteor. Soc., 87, 523-534, https:// doi.org/10.1002/qj.49708737407.

Aydin, K., and Y. Zhao, 1990: A computational study of polarimetric radar observables in hail. IEEE Trans. Geosci. Remote Sens., 28, 412-422, https://doi.org/10.1109/TGRS.1990.572906.

_ , V. Giridhar, and Y. Zhao, 1991: Polarimetric C-band radar observables in melting hail: A computational study. Preprints, 25th Int. Conf. on Radar Meteorology, Paris, France, Amer. Meteor. Soc., 23.9

Balakrishnan, N., and D. Zrnić, 1990: Use of polarization to characterize precipitation and discriminate large hail. J. Atmos. Sci., 47, 1525-1540, https://doi.org/10.1175/1520-0469(1990) 047<1525:UOPTCP > 2.0.CO;2.

Bodine, D., R. Palmer, and G. Zhang, 2014: Dual-wavelength polarimetric radar analyses of tornadic debris signatures. J. Appl. Meteor. Climatol., 53, 242-261, https://doi.org/10.1175/ JAMC-D-13-0189.1.

Bringi, V. N., and V. Chandrasekar, 2001: Polarimetric Doppler Weather Radar Principles and Applications. Cambridge University Press, $636 \mathrm{pp}$.

_ J. Vivekanandan, and J. Tuttle, 1986a: Multiparameter radar measurements in Colorado convective storms. Part I: Hai detection studies. J. Atmos. Sci., 43, 2545-2563, https://doi.org/ 10.1175/1520-0469(1986)043<2545:MRMICC>2.0.CO;2.

_, R. Rasmussen, and J. Vivekanandan, 1986b: Multiparameter radar measurements in Colorado convective storms. Part II Graupel melting studies. J. Atmos. Sci., 43, 2564-2577, https://
doi.org/10.1175/1520-0469(1986)043<2564:MRMICC> 2.0. $\mathrm{CO} ; 2$

- T. Keenan, and V. Chandrasekar, 2001: Correcting C-band radar reflectivity and differential reflectivity data for rain attenuation: A self-consistent method with constraints. IEEE Trans. Geosci. Remote Sens., 39, 1906-1915, https://doi.org/ 10.1109/36.951081.

Brunkow, D., V. Bringi, P. Kennedy, S. Rutledge, V. Chandrasekar, E. Mueller, and R. Bowie, 2000: A description of the CSUCHILL national radar facility. J. Atmos. Oceanic Technol., 17, 1596-1608, https://doi.org/10.1175/1520-0426(2000)017<1596: ADOTCC $>2.0 . C O ; 2$.

Carbone, R., D. Atlas, P. Eccles, R. Fetter, and E. Mueller, 1973: Dual-wavelength radar hail detection. Bull. Amer. Meteor. Soc., 54, 921-924, https://doi.org/10.1175/1520-0477(1973) 054<0921:DWRHD>2.0.CO;2.

Carey, L. D., S. Rutledge, D. Ahijevych, and T. Keenan, 2000: Correcting propagation effects in C-band polarimetric radar observations of tropical convection using differential propagation phase. J. Appl. Meteor., 39, 14051433, https://doi.org/10.1175/1520-0450(2000)039<1405: CPEICB $>2.0 . \mathrm{CO} ; 2$.

Conway, J., and D. Zrnić, 1993: A study of embryo production and hail growth using dual-Doppler and multiparameter radars. Mon. Wea. Rev., 121, 2511-2528, https://doi.org/10.1175/ 1520-0493(1993)121<2511:ASOEPA > 2.0.CO;2.

Delrieu, G., S. Caoudal, and J. Creutin, 1997: Feasibility of using mountain return for the correction of ground-based X-band weather data. J. Atmos. Oceanic Technol., 14, 368-385, https:// doi.org/10.1175/1520-0426(1997)014<0368:FOUMRF> 2.0. CO; 2

Doviak, R., and D. S. Zrnić, 1993: Doppler Radar and Weather Observations. Dover Publications, 562 pp.

Eccles, P., and E. Mueller, 1971: X-band attenuation and liquid water content estimation by a dual-wavelength radar. J. Appl. Meteor., 10, 1252-1259, https://doi.org/10.1175/1520-0450(1971) $010<1252$ :XBAALW $>2.0 . \mathrm{CO} ; 2$.

- , and D. Atlas, 1973: A dual-wavelength radar hail detector. J. Appl. Meteor., 12, 847-854, https://doi.org/10.1175/ 1520-0450(1973)012<0847:ADWRHD>2.0.CO;2.

Ellis, S., and J. Vivekanandan, 2010: Water vapor estimates using simultaneous dual wavelength radar observations. Radio Sci., 45, RS5002, https://doi.org/10.1029/2009RS004280.

Gaussiat, N., H. Sauvageot, and A. Illingworth, 2003: Cloud liquid water and ice content retrieved by multiwavelength radar. J. Atmos. Oceanic Technol., 20, 1264-1275, https://doi.org/ 10.1175/1520-0426(2003)020<1264:CLWAIC >2.0.CO;2.

Gu, J., A. Ryzhkov, P. Zhang, P. Neilley, M. Knight, B. Wolf, and D. Lee, 2011: Polarimetric attenuation correction in heavy rain at C band. J. Appl. Meteor. Climatol., 50, 39-58, https:// doi.org/10.1175/2010JAMC2258.1.

Herzegh, P. H., and A. R. Jameson, 1992: Observing precipitation through dual-polarization radar measurements. Bull. Amer. Meteor. Soc., 73, 1365-1374, https://doi.org/10.1175/1520-0477(1992) 073<1365:OPTDPR $>2.0$. CO;2.

Jameson, A., and R. Srivastava, 1978: Dual-wavelength Doppler radar observations of hail at vertical incidence. J. Appl. Meteor., 17, 1694-1703, https://doi.org/10.1175/1520-0450(1978) 017<1694:DWDROO>2.0.CO;2.

, and A. Heymsfield, 1980: Hail growth mechanisms in a Colorado hailstorm. Part I: Dual-wavelength radar observations. J. Atmos. Sci., 37, 1763-1778, https://doi.org/10.1175/ 1520-0469(1980)037<1763:HGMIAC >2.0.CO;2. 
Junyent, F., and V. Chandrasekar, 2016: An examination of precipitation using CSU-CHILL dual-wavelength, dual-polarization radar observations. J. Atmos. Oceanic Technol., 33, 313-329, https://doi.org/10.1175/JTECH-D-14-00229.1.

,,-- V. Bringi, S. Rutledge, P. Kennedy, D. Brunkow, J. George, and R. Bowie, 2015: Transformation of the CSUCHILL radar facility to a dual-frequency, dual-polarization Doppler system. Bull. Amer. Meteor. Soc., 96, 975-996, https:// doi.org/10.1175/BAMS-D-13-00150.1.

Kneifel, S., A. V. Lerber, J. Tiira, D. Moisseev, P. Kollias, and J. Leinonen, 2015: Observed relations between snowfall microphysics and triple-frequency radar measurements. J. Geophys. Res. Atmos., 120, 6034-6055, https://doi.org/ 10.1002/2015JD023156.

Knight, N., 1986: Hailstone shape factor and its relation to radar interpretation of hail. J. Climate Appl. Meteor., 25, 1956-1958, https://doi.org/10.1175/1520-0450(1986)025<1956:HSFAIR> 2.0.CO;2.

Kumjian, M., and A. Ryzhkov, 2008: Polarimetric signatures in supercell thunderstorms. J. Appl. Meteor. Climatol., 47, 19401961, https://doi.org/10.1175/2007JAMC1874.1.

Levenberg, K., 1944: A method for the solution of certain problems in least squares. Quart. Appl. Math., 2, 164-168, https:// doi.org/10.1090/qam/10666.

Louf, V., O. Pujol, H. Sauvageot, and J. Riedi, 2014: The dualwavelength method for hailstorm detection by airborne radar. IEEE Trans. Geosci. Remote Sens., 52, 7327-7335, https:// doi.org/10.1109/TGRS.2014.2311316.

Marquardt, D., 1963: An algorithm for least-squares estimation of nonlinear parameters. SIAM J. Appl. Math., 11, 431-441, https://doi.org/10.1137/0111030.

Miller, L., J. Tuttle, and C. Knight, 1988: Airflow and hail growth in a severe northern High Plains supercell. Mon. Wea. Rev., 45, 736-762, https://doi.org/10.1175/1520-0469(1988)045<0736: AAHGIA $>2.0 . \mathrm{CO} ; 2$.

Musil, D., A. Heymsfield, and P. Smith, 1986: Microphysical characteristics of a well-developed weak echo region in a High Plains supercell thunderstorm. J. Climate Appl. Meteor., 25, 1037-1051, https://doi.org/10.1175/1520-0450(1986)025<1037: MCOAWD $>2.0 . \mathrm{CO} ; 2$.

Park, S., M. Maki, K. Iwanami, V. Bringi, and V. Chandrasekar, 2005: Correction of radar reflectivity and differential reflectivity for rain attenuation at X band. Part II: Evaluation and application. J. Atmos. Oceanic Technol., 22, 1633-1655, https://doi.org/10.1175/JTECH1804.1.

Picca, J., and A. Ryzhkov, 2012: A dual-wavelength polarimetric analysis of the 16 May 2010 Oklahoma City extreme hailstorm. Mon. Wea. Rev., 140, 1385-1403, https://doi.org/10.1175/ MWR-D-11-00112.1.

Rasmussen, R., and A. Heymsfield, 1987: Melting and shedding of graupel and hail. Part I: Model physics. J. Atmos. Sci., 44, 2754-2763, https://doi.org/10.1175/1520-0469(1987)044<2754: MASOGA $>2.0 . \mathrm{CO} ; 2$.

Rinehart, R., and J. Tuttle, 1982: Antenna beam patterns and dual-wavelength processing. J. Appl. Meteor., 21, 18651880, https://doi.org/10.1175/1520-0450(1982)021<1865: ABPADW $>2.0 . \mathrm{CO} ; 2$.

Ryzhkov, A., D. Hudak, and J. Scott, 2006: A new polarimetric scheme for attenuation correction at $\mathrm{C}$ band. Fourth European
Conf. on Radar in Meteorology and Hydrology, Barcelona, Spain, Center of Applied Research in Hydrometeorology, 29-32.

— , P. Zhang, D. Hudak, J. Alford, M. Knight, and J. Conway, 2007: Validation of polarimetric methods for attenuation correction at $\mathrm{C}$ band. 33rd Conf. on Radar Meteorology, Cairns, Australia, Amer. Meteor. Soc., P11B.12, https:// ams.confex.com/ams/33Radar/techprogram/paper_123122.htm.

__- M. Kumjian, S. Ganson, and A. Khain, 2013a: Polarimetric radar characteristics of melting hail. Part I: Theoretical simulations using spectral microphysical modeling. J. Appl. Meteor. Climatol., 52, 2849-2870, https://doi.org/10.1175/ JAMC-D-13-073.1.

,,--- , and P. Zhang, 2013b: Polarimetric radar characteristics of melting hail. Part II: Practical implications. J. Appl. Meteor. Climatol., 52, 2871-2886, https://doi.org/10.1175/ JAMC-D-13-074.1.

Seliga, T., and V. Bringi, 1976: Potential use of radar differential reflectivity measurements at orthogonal polarizations for measuring precipitation. J. Appl. Meteor., 15, 69-76, https:// doi.org/10.1175/1520-0450(1976)015<0069:PUORDR > 2.0. $\mathrm{CO} ; 2$.

—, and - 1978: Differential reflectivity and differential phase shift: Applications in radar meteorology. Radio Sci., 13, 271-275, https://doi.org/10.1029/RS013i002p00271.

Testud, J., E. L. Bouar, E. Obligis, and M. Ali-Mehenni, 2000: The rain profiling algorithm applied to polarimetric weather radar. J. Atmos. Oceanic Technol., 17, 332-356, https://doi.org/ 10.1175/1520-0426(2000)017<0332:TRPAAT > 2.0.CO;2.

Trapp, R., D. Wheatley, N. Atkins, R. Przybylinski, and R. Wolf, 2006: Buyer beware: Some words of caution on the use of severe wind reports in postevent assessment and research. Wea. Forecasting, 21, 408-415, https://doi.org/10.1175/ WAF925.1.

Tridon, F., A. Battaglia, and P. Kollias, 2013: Disentangling Mie and attenuation effects in rain using a $\mathrm{K}_{a}$-W dual-wavelength Doppler spectral ratio technique. Geophys. Res. Lett., 40, 5548-5552, https://doi.org/10.1002/2013GL057454.

,,-- E. Luke, and P. Kollias, 2017: Rain retrieval from dualfrequency radar Doppler spectra: Validation and potential for a midlatitude precipitating case study. Quart. J. Roy. Meteor. Soc., 143, 1364-1380, https://doi.org/10.1002/qj.3010.

Trömel, S., M. R. Kumjian, A. V. Ryzhkov, C. Simmer, and M. Diederich, 2013: Backscatter differential phase-Estimation and variability. J. Appl. Meteor. Climatol., 52, 2529-2548, https://doi.org/10.1175/JAMC-D-13-0124.1.

Tuttle, J., and R. Rinehart, 1983: Attenuation correction in dualwavelength analyses. J. Climate Appl. Meteor., 22, 1914-1921, https://doi.org/10.1175/1520-0450(1983)022<1914:ACIDWA > 2.0.CO;2.

_ radar study of a microburst: Comparison with model results. J. Atmos. Sci., 46, 601-620, https://doi.org/10.1175/15200469(1989)046<0601:MRSOAM > 2.0.CO;2.

Vivekanandan, J., V. Bringi, and R. Raghavan, 1990: Multiparameter radar modeling and observations of melting ice. J. Atmos. Sci., 47, 549-564, https://doi.org/10.1175/1520-0469(1990) 047<0549:MRMAOO>2.0.CO;2. 